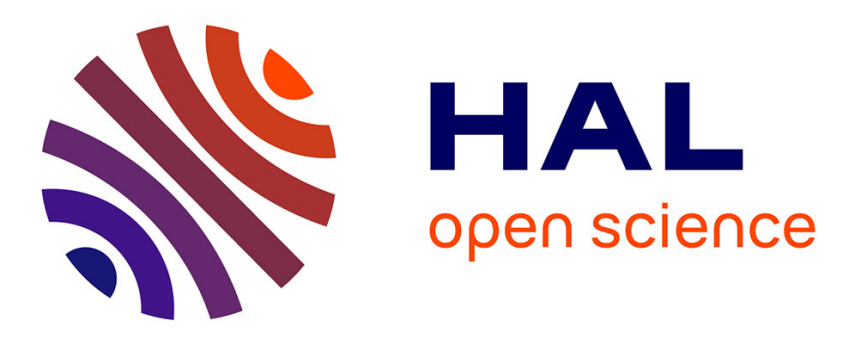

\title{
Flowability characterization of torrefied biomass powders: static and dynamic testing
}

John Pachón-Morales, Julien Colin, Joel Casalinho, Patrick Perre, François

Puel

\section{- To cite this version:}

John Pachón-Morales, Julien Colin, Joel Casalinho, Patrick Perre, François Puel. Flowability characterization of torrefied biomass powders: static and dynamic testing. Biomass and Bioenergy, 2020, 138, pp.105608. 10.1016/j.biombioe.2020.105608 . hal-02903554

\section{HAL Id: hal-02903554 \\ https://hal.science/hal-02903554}

Submitted on 21 Jul 2020

HAL is a multi-disciplinary open access archive for the deposit and dissemination of scientific research documents, whether they are published or not. The documents may come from teaching and research institutions in France or abroad, or from public or private research centers.
L'archive ouverte pluridisciplinaire HAL, est destinée au dépôt et à la diffusion de documents scientifiques de niveau recherche, publiés ou non, émanant des établissements d'enseignement et de recherche français ou étrangers, des laboratoires publics ou privés. 
This Accepted author version available online: $2020,2^{\text {nd }}$ of June.

To cite this article: John Pachón-Morales, Julien Colin, Joel Casalinho, Patrick Perré, François Puel (2020) Flowability characterization of torrefied biomass powders : static and dynamic testing. Biomass and Bioenergy, 138, 105608, DOI: https://doi.org/10.1016/j.biombioe.2020.105608

\title{
Flowability characterization of torrefied biomass
}

\section{powders: static and dynamic testing}

\author{
John Pachón-Morales a ${ }^{*}$, Julien Colin a,b, Joel Casalinho a, Patrick Perré a,b, François Puel a \\ a LGPM, CentraleSupélec, Université Paris-Saclay, 3 rue Joliot-Curie, 91192 Gif-sur-Yvette, France \\ b LGPM, CentraleSupélec, Université Paris-Saclay, SFR Condorcet FR CNRS 3417, Centre Européen de Biotechnologie et de \\ Bioéconomie (CEBB), 3 rue des Rouges Terres, 51110 Pomacle, France
}

\begin{abstract}
During the thermochemical valorization of biomass feedstock, the assessment of biomass powder flowability is essential for the design of feeding, storage, and handling systems. Biomass handling in valorization processes require powders to be characterized for both consolidated and static conditions, encountered in storage facilities, or under free-surface dynamic flow conditions, present in feeding systems. This paper evaluated the flow properties of two different sizes of raw, mildly and intensively torrefied poplar powders, using shear tests and the evaluation of avalanching behaviors, in a rotating drum. The size and shape descriptors showed that the particle size distributions and particle morphologies of the six samples were determined by the coupled effects of torrefaction intensity and the sieving stage. According to the shear test results, although flowability trends are stress-dependent, coarse powders have better flow properties than fine powders. A flowability ranking was established, based on the parameters extracted from the flow dynamics inside of a rotating drum, including the tendency to form particle clumps, upper angle of stability, irregularity of avalanches, and the fraction of revolution for avalanches. The relationships among the macroscopic flow parameters, obtained from both characterization techniques and the powder characteristics (particle mean size, shape, and polydispersity) were examined using adjusted correlations. Overall, intense torrefaction appears to improve the flow behaviors of powders, under both free and consolidated flow conditions.
\end{abstract}

\footnotetext{
* Corresponding author:

E-mail addresses: (J. Pachón-Morales) john.pachon@centralesupelec.fr, (F. Puel) francois.puel@,centralesupelec.fr
} 


\section{Keywords:}

Ring shear tester, rotating drum, torrefaction, flow properties, cohesion, woody biomass

\section{INTRODUCTION}

The thermochemical conversion of lignocellulosic biomass, through gasification, is a promising method for reducing fossil fuel consumption. Recent studies have shown the attractiveness of using entrained-flow reactors during the gasification of biomass. This technology is commercially available on a large scale (for coal and liquid fuels) and yields the maximum efficiency for the conversion of biomass to syngas [1]. The short residence times associated with entrained-flow gasification demand sub-millimeter sized feedstocks, to optimize the fuel injection into the gasifier and increase chemical reactivity [1]. The optimal performance of gasifiers requires stable and steady feeding rates, which may be particularly difficult to achieve when using biomass feedstocks, given their fibrous, flaky, and cohesive behavior. Flow fluctuations, bridging, and blockages of biomass particles in gasifier feeding systems are common industrial problems that can trigger temperature excursions and fluctuations in the fuel gas constituents [2,3].

Although the standard procedures for silo design, based on the theories by Jenike and Janssen [4], have been successfully used for decades, the key causes of many handling problems can be linked to the lack of holistic and meaningful bulk characterization at the earliest stages of equipment design. To provide a basis for the design of troublefree, powdered biomass handling, storage, and transportation systems, flowability characterizations, performed under different flow conditions, are essential. Poor powder flowability problems can occur under a range of flow and stress conditions: static or dynamic, compacted or loose packing. Powder storage in silos represents a static and compacted configuration, whereas problems associated with fluidization and pneumatic or mechanical transportation represent dynamic, free-surface, and loose-packing conditions. Due to the complexity of granular materials, which can vary depending on the conditioning state, no simple or single method can fully characterize flow behavior. Therefore, a wide variety of flow characterization methods and criteria have been presented in the literature [137]. The most common method is the shear tester, which measures the force required to shear a powder under well-defined conditions. Shear tests and avalanching studies, performed in rotating drums, are commonly used to characterize compacted, quasi-static states and dynamic, free-surface states, respectively.

Although shear testing is often referred to as a relatively time-consuming method [5], it is the most frequently used method for the characterization of powder flow under consolidation conditions. This method provides the 
powder's yield loci, from which cohesion, yield strength, internal friction, and flow functions can be determined [6]. These properties are useful for designing storage facilities and feeding systems. Though scarce, recent studies reporting biomass flowability measurements using shear testers include the study by Miccio et al. [7], who found that the flow properties of particulate biomass (ground olive husks and sawdust) could be reliably measured by shear cells when the particle size is below $2 \mathrm{~mm}$. In another study, using a comminuted poplar and corn stover $\left(d_{p}<5 \mathrm{~mm}\right)$, Gil et al. [8] found that lower particle sizes improved flow behaviors, due to the reduced presence of hooked particles, whereas higher moisture contents led to the increased tendency to form arches or ratholes. Guo et al. [9] showed that the addition of biomass (rice straw and sawdust) to coal had no effects on cohesion strength but significantly increased internal friction. Additional research, using ground agricultural materials, include the studies by Littlefield et al. [10], examining ground pecan shells, and Chevanan et al. [11] and Crawford et al. [12], examining pre-treated and wet corn stover.

Rotating drums allow the dynamic behaviors of granular materials to be studied under low-stress conditions. The test does not require expensive sample preconditioning, can be performed quickly, and can be repeated many times, without operator intervention. Moreover, rotating drums can detect powder additive-induced changes in powder flowability more accurately and with greater reproducibility than other tests, such as the angle-of-repose and bulk density measurements [13]. These advantages have propelled the use of rotating drum systems for the analysis of powder flowability. Although the overwhelming majority of work using rotating drums has focused on non-cohesive materials [14-17], recent studies [17-22] have highlighted the usefulness of studying avalanche behaviors to assess the flowability of cohesive powders, such as moist pharmaceutical [23] and cocoa [24] powders. Avalanching behaviors have been correlated with the discharge rates at the outlets of biomass screw feeders [25]. The avalanche characterization of biomass powder, which has a recognized cohesive character, could provide new insights into the dynamic, free-surface flow behaviors of this material.

In addition to slurries and dissolved woods, torrefied powders are one of the basic forms of wood that are suitable for feeding entrained-flow gasifiers [26]. Biomass torrefaction refers to a pretreatment process that improves fuel characteristics, in terms of energy density, hydrophobicity, and physicochemical stability [1]. Torrefaction consists of a mild pyrolysis process, performed at temperatures ranging from $200-300^{\circ} \mathrm{C}$, under anoxic atmospheric conditions and at a relatively low particle-heating rate $\left(\right.$ less than $\left.1^{\circ} \mathrm{C} \cdot \mathrm{s}^{-1}\right)$. Several studies have highlighted the ability of torrefaction to increase the grindability of woody biomass, reducing the energy consumption required for milling to $10 \%$ of the energy required for raw biomass processing [27-29]. Previous research has suggested that torrefaction may also 
improve biomass flow properties, as measured by a shear tester [30], primarily due to the increase in particle circularity associated with torrefaction intensity.

Particle sizes and shapes have been confirmed to have significant influences on flow properties, especially among biomass materials. Mattson and Kofman [31] found that the most important property for determining the bridging tendencies in solid biomass samples was particle shape. Poor flow was directly related to the contents of hooked or long, thin particles. The combined effects of particle sizes and shapes on bridging tendencies, yield strengths, and bulk densities were observed by Paulrud et al., among pine and spruce powders [32], and by Gil et al., for short rotation forestry (SRF) poplar and corn stover [8]. Because different biomass materials do not have the same compositions or structures, the flow properties and responses to changes in particle sizes and shapes may vary depending on the material and pretreatment processes used, such as torrefaction.

This study aimed to assess the flow behaviors of raw and torrefied biomass powders, using two characterization techniques representative of compacted and free-surface stress states. The effects of particle properties, such as particle sizes and shapes, on the bulk behaviors of the examined powders were also determined. This study was performed as a component of the discrete element modeling (DEM) of the flow of biomass particles in a rotating drum, conducted by the authors [33]. Broad particle size distributions (PSDs) can significantly increase the run times of DEM simulations; therefore, the first stage of this study consisted of reducing the polydispersity of milled powders, by sieving a grinder outflow, which facilitated the experimental and numerical evaluation of the effects of two well-differentiated size distributions on the flow behaviors of biomass powders.

\section{MATERIALS AND METHODS}

\subsection{Biomass powder preparation}

Poplar (Populus euro-americana 'Koster') was chosen as a representative lignocellulosic biomass because it is a promising energy crop, due to its rapid growth in temperate climates. In addition, the development of poplar genotypes with improved yields, increased pest resistance properties, increased site adaptability, and easy vegetative propagation has made poplar a commercially valuable energy crop [34,35]. The poplar tree selected for this study (25 years old, basic density of $311 \pm 9 \mathrm{~kg} \cdot \mathrm{m}^{-3}$, growth ring width of $14 \times 10^{-3} \mathrm{~m}$ ) came from a forest located in La Suippe valley, in Auménancourt-le-Petit, France. The tree was felled and cut into boards that were subsequently dried. Samples, sized $0.06 \times 0.08 \times 0.015 \mathrm{~m}^{3}$, were cut from the boards. 


\subsubsection{Torrefaction}

A batch torrefaction furnace, which was specifically developed in our laboratory, was used to thermally treat the samples [36]. The atmosphere of a hermetically sealed Memmert UFP400 chamber was controlled using a nitrogen stream $\left(5 \mathrm{~L} \mathrm{~min}^{-1}\right)$, to reduce the oxygen contents and avoid oxidation and ignition. In all cases, the oxygen level measured at the gas outlet remained below 1.5\%. A powerful fan inside the chamber ensured efficient heat transfer, either to heat the sample or to limit thermal overheating, due to exothermic reactions. The gas temperature was measured in the vicinity of the samples, using a K-thermocouple. Two treatments were performed, at $240^{\circ} \mathrm{C}$ and $280^{\circ} \mathrm{C}$, for 1 hour, using the following protocol. (i) Heating was performed from room temperature, at a rate of $10^{\circ} \mathrm{C} \cdot \mathrm{min}^{-1}$, until a temperature of $103^{\circ} \mathrm{C}$ was achieved. (ii) A temperature of $103^{\circ} \mathrm{C}$ was maintained for 12 hours, to remove residual bound water. (iii) Heating was performed at a rate of $10^{\circ} \mathrm{C} \cdot \mathrm{min}^{-1}$ until the treatment temperature was achieved. (iv) The treatment temperature was maintained for 1 hour. (v) Finally, cooling was achieved through a combination of thermal losses and increased nitrogen flow into the reactor. Preliminary experiments [37] and simulations based on a comprehensive computational code [38] were performed, to ensure that the treatment duration, together with the sample thickness, ensures the quasi-uniformity of the treatment conditions within the sample. Approximately 20 poplar woodchips were simultaneously treated at each temperature level.

After treatment, the samples were weighed to determine the mass loss $(M L)$ due to heat treatment, as follows:

$$
M L(\%)=\frac{m_{0}-m_{t}}{m_{0}} \cdot 100
$$

here, $m_{0}$ and $m_{t}$ are the oven-dried mass before and after torrefaction, respectively. Mass loss is known to be a good indicator of the treatment intensity and has been successfully correlated with several properties of treated biomass, including energy properties [39], dimensional changes [40], and flowability [41]. Mass losses of $9.6 \pm 0.8 \%$ and $24.5 \pm 3 \%$ were obtained for samples treated at $240^{\circ} \mathrm{C}$ and $280^{\circ} \mathrm{C}$, respectively.

\subsubsection{Grinding and sieving}

Raw and torrefied materials were ground, using a Retsch SM300 cutting mill, with a bottom sieve comprised of 1$\mathrm{mm}$ trapezoidal holes at the outlet. Powders obtained after grinding were sieved to obtain two well-differentiated sieving cuts, which were representative of coarse and fine particles. A vibratory sieve shaker, Retsch AS 200, at an amplitude of $60 \%(1.8 \mathrm{~mm})$ was used for 20 minutes, and sieves with $500-\mu \mathrm{m}$ and $710-\mu \mathrm{m}$ openings were used to separate the coarse cut, whereas sieves with $200-\mu \mathrm{m}$ and $315-\mu \mathrm{m}$ openings were used to separate the fine cut. 


\subsection{Particle size and shape measurements}

A Sympate-QICPIC [42] morphological particle size analyzer was used to obtain biomass PSDs after sieving. The values of the descriptors for the particle size and shape distributions are listed in Table 1. The minimum value of the Feret diameter, across all orientations of the particle, is used to characterize the particle size $\left(d_{p}\right)$. The $50^{\text {th }}$ percentile of the cumulative volume distributions $\left(d_{50}\right)$ is used as the mean size descriptor for each size distribution. The PSD span $\left(S_{x}\right)$ was calculated from values of the $90^{\text {th }}$ and $10^{\text {th }}$ percentiles, as follows:

$$
S_{x}=\left(d_{p_{90}}-d_{p_{10}}\right) /\left(d_{p_{90}}+d_{p_{10}}\right)
$$

Particle shape was characterized using two shape descriptors: (i) the aspect ratio, $a(0 \leq a \leq 1)$, which is defined as the ratio between the minimum and the maximum Feret diameters; and (ii) the circularity $\Phi(0 \leq \Phi \leq 1)$, which is defined as the ratio of the perimeter of a circle with the same area of the particle to the perimeter of the projected area of the particle. A perfect circular projection would result in $\Phi=1$, whereas smaller $\Phi$ values indicate more irregular or rough shapes. Mean values of the aspect ratio and circularity ( $a_{50}$ and $\Phi_{50}$, respectively) were obtained from the $50^{\text {th }}$ percentiles of the cumulative shape distributions, and the shape descriptor span was defined as follows:

$$
S_{\psi}=\left(\psi_{90}-\psi_{10}\right) /\left(\psi_{90}+\psi_{10}\right)
$$

where $\psi_{90}$ and $\psi_{10}$ correspond respectively to the $90^{\text {th }}$ and $10^{\text {th }}$ percentiles of the $\psi$ shape descriptor distribution, either aspect ratio (a) or circularity $(\Phi)$.

Table 1. Powder size and shape descriptors.

\begin{tabular}{ccccccccccccc}
\hline $\begin{array}{c}\text { Sample } \\
\text { ID }\end{array}$ & Description & $\begin{array}{c}\text { Torrefaction } \\
\text { temperature }\end{array}$ & $\begin{array}{c}M L \\
(\%)\end{array}$ & $\begin{array}{c}\text { Sieving cut } \\
(\mu \mathrm{m})\end{array}$ & $\begin{array}{c}d p_{50} \\
(\mu \mathrm{m})\end{array}$ & $\begin{array}{c}d p_{90} \\
(\mu \mathrm{m})\end{array}$ & $\begin{array}{c}d p_{10} \\
(\mu \mathrm{m})\end{array}$ & $\begin{array}{c}S_{x} \\
a_{50}\end{array}$ & $\begin{array}{c}S_{a} \\
\Phi_{50}\end{array}$ & $S_{\Phi}$ \\
\hline 1 & Raw coarse & Untreated & 0 & $500-710$ & 746 & 1092 & 519 & 0.36 & 0.38 & 0.49 & 0.63 & 0.28 \\
2 & Raw fine & Untreated & 0 & $200-315$ & 352 & 513 & 243 & 0.36 & 0.42 & 0.53 & 0.59 & 0.34 \\
3 & $M L=9.6 \%$ coarse & $240^{\circ} \mathrm{C}$ & 9.6 & $500-710$ & 667 & 929 & 448 & 0.35 & 0.31 & 0.56 & 0.59 & 0.31 \\
4 & $M L=9.6 \%$ fine & $240^{\circ} \mathrm{C}$ & 9.6 & $200-315$ & 320 & 440 & 224 & 0.33 & 0.33 & 0.58 & 0.57 & 0.35 \\
5 & $M L=24.5 \%$ coarse & $280^{\circ} \mathrm{C}$ & 24.5 & $500-710$ & 526 & 862 & 303 & 0.48 & 0.41 & 0.50 & 0.69 & 0.23 \\
6 & $M L=24.5 \%$ fine & $280^{\circ} \mathrm{C}$ & 24.5 & $200-315$ & 253 & 370 & 162 & 0.39 & 0.43 & 0.56 & 0.68 & 0.26 \\
\hline
\end{tabular}


a.

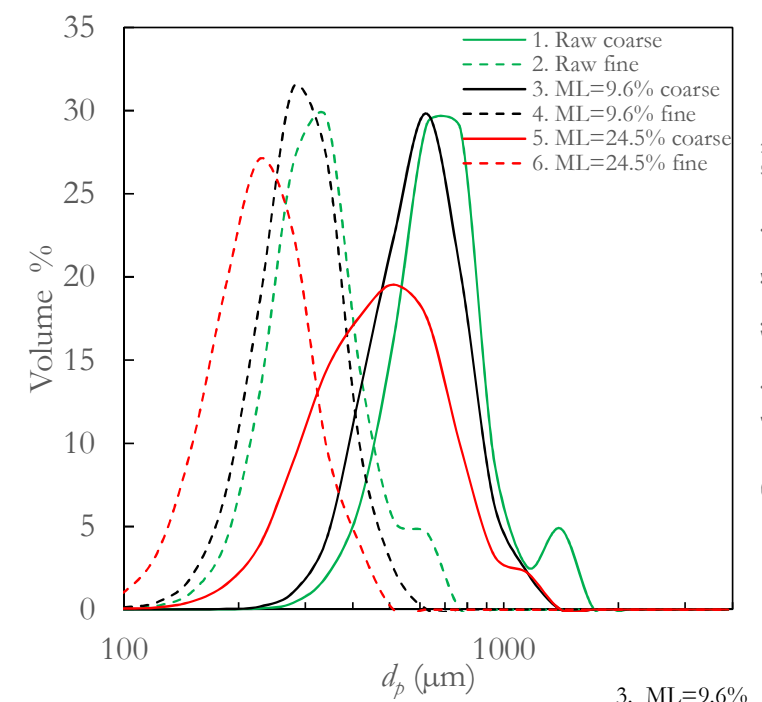

b.

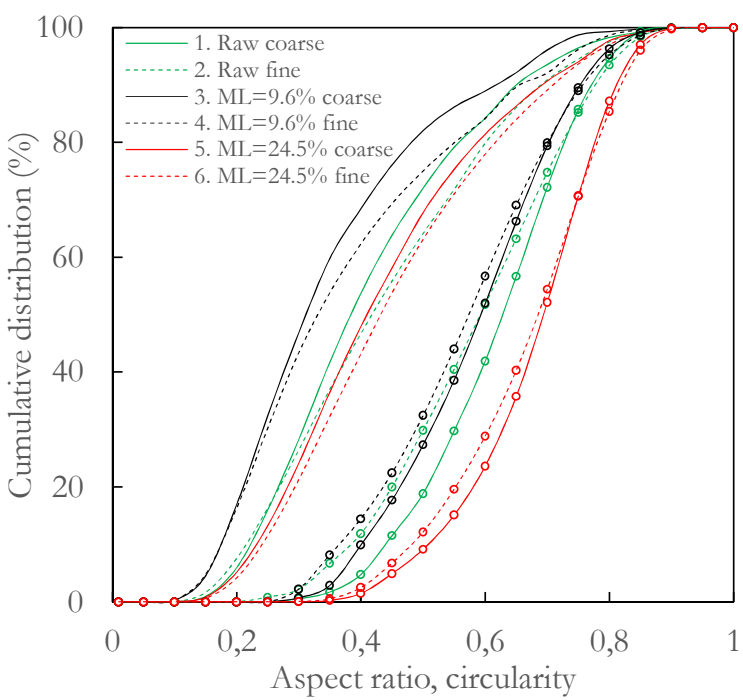

C.

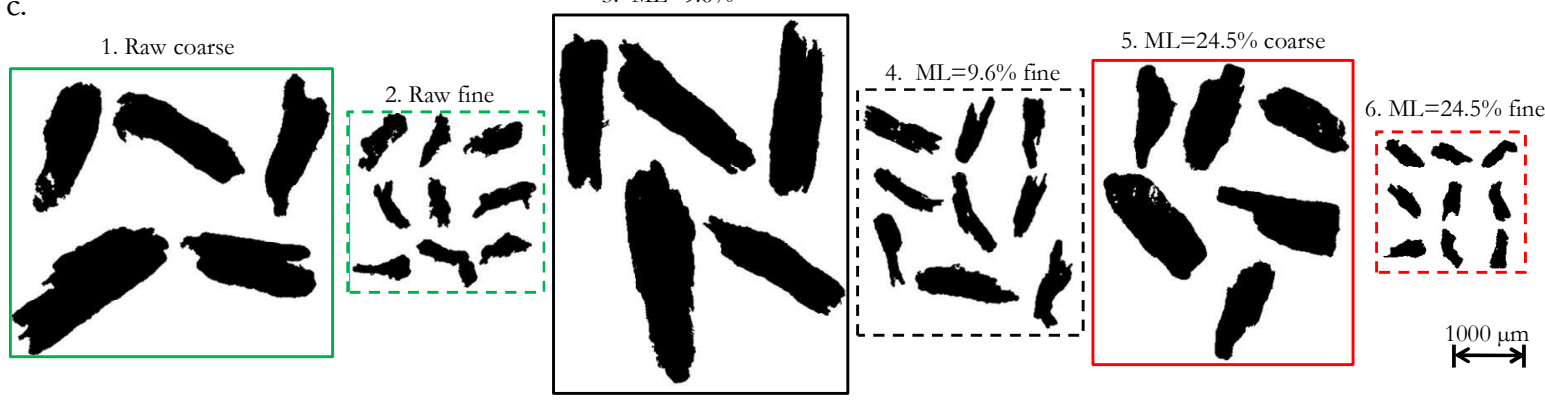

Figure 1. Biomass size and shape characteristics. a. Particles size distribution, b. Aspect ratio a (series without marker) and circularity $\phi$ (series with circular marker)

distributions, c. Examples of particle shapes for each sample.

The data reported in Table 1 and Figure 1a show that, although a sieving stage reduces the polydispersity of the grinder's outflow, creating two well-distinguished populations for each torrefaction intensity, similar sieving cuts do not necessarily have present similar characteristics. Raw and mildly torrefied samples had relatively similar particle sizes, whereas the most intensively torrefied samples had smaller particles and broader distributions. Similar trends were observed for both the coarse and fine sieving cuts. These differences are the likely consequence of the increased brittleness of torrefied samples after $24.5 \% \mathrm{ML}$, which could result in the occurrence of particle breakage and fine particle generation during the sieving process. Similar PSDs were observed for raw and mildly torrefied samples, indicating the occurrence of an abrupt change in brittleness between samples with $9.6 \%$ ML and those with $24.5 \%$ ML.

Particle shape also depended on both the torrefaction intensity and the sieving cuts (Figure 1b and c). Small particles were less elongated (lower aspect ratio), with a more irregular surface (lower circularity) than coarse particles. Intensively torrefied powders had rounder and less elongated particles than raw and mildly torrefied samples. Samples torrefied at $M L=9.6 \%$ had the most needle-shaped and rough particles. 
All powders were oven-dried at $103^{\circ} \mathrm{C}$, for at least 24 hours, before performing flowability tests.

\subsection{Flowability tests}

\subsubsection{Ring shear tester}

An RST-XS Schulze ring shear tester [6,43] was used to assess the flow properties of the biomass powders under consolidation conditions. The ring shear tester is a widely-used device for measuring the flowability of powders, including unconfined yield strength $\left(\sigma_{c}\right)$, the major principal stress of consolidation $\left(\sigma_{1}\right)$, and the flowability factor $(F F C)$. The standard procedure leads to results with low variability [6]. A brief overview of the theory behind these tests and some specificities related to tests on biomass powders are presented in the appendix. A set of three pre-consolidation stresses $\left(\sigma_{p r e}\right)$ were tested, which were considered to be representative of the stress ranges for industrial applications: 2 , 5 , and $10 \mathrm{kPa}[36]$. Three shear points $\left(\sigma_{s h}\right)$, at 25, 50, and 75\% of the $\sigma_{\text {pre }}$ value for each pre-consolidation stress, were used to determine the yield locus of each sample. The yield locus curves were regressed from experimental points by a linear regression. Shear and rotating drum tests were replicated three times, using different samples of treated biomass batches.It

The unconfined yield strength governs the stress that holds the materials together on a free surface. It is the major principle stress, acting in a direction parallel to the free surface, which supports the external forces that tend to tear the surface apart [37]. Larger unconfined yield strengths require higher strengths to fail or fracture the granular material and initialize the flow. The unconfined yield strength indicates the tendency of a bulk solid to form a cohesive arch in a hopper and to form ratholes in processing equipment [12]. The FFC (flow function coefficient) ratio between consolidation stress and unconfined stress $\left(F F C=\sigma_{1} / \sigma_{c}\right)$ is used to quantify the flowability. In general, larger $F F C$ values are associated with a better bulk solid flow. All properties obtained from the Schulze ring shear tester are usually reported as a function of the major principal stress of consolidation $\left(\sigma_{1}\right)$.

\subsubsection{Dynamic free-surface conditioning: rotating drum experiments}

Rotating drums testers are considered to represent the most practical geometry for studying the flow of granular materials. Compared with powder rheometers, which are based on shear measurements, the only stress applied to powder samples in a rotating system is induced by gravity, which acts on the powder mass. The results of avalanching 
measurements better represent the real stress conditions of powders flowing in a pipe or being handled by a conveying screw.

An in-house experimental device was developed to characterize the dynamics of biomass sample avalanches. The core component is a stainless-steel cylinder (10-cm inner diameter, $2-\mathrm{cm}$ width), that is clamped inside of a roller bearing, as shown in Figure 2a. This design ensures a regular and smooth rotation, without vibrations, and permits the uniform lighting necessary to obtain high-quality images. Two transparent, conductive, indium-tin-oxide (ITO)-coated glass discs are used to enhance the drainage of static electricity. The drive mechanism, which was built between a motor and the cylinder housing, consists of two pulleys, connected by a toothed belt. This configuration ensures a steady and stable rotational speed, which can range between $0.00016 \mathrm{~s}^{-1}$ and $1.22 \mathrm{~s}^{-1}$ for the chosen pulley-belt set.

Image acquisitions were performed using a Photron FASTCAM high-speed camera, at a framerate of 50 fps, over $355 \mathrm{~s}$, with a resolution of $896 \times 720$. Image post-processing was performed to obtain the powder surface profile over time. To automatically process the large set of images obtained during each test (typically approximately 18,000 images per test), the entire procedure was implemented using the Image Processing Toolbox ${ }^{\text {TM }}$ in the MATLAB platform. Details regarding the setup, the definition of the best criteria for assessing flowability, and preliminary tests for noncohesive and cohesive materials can be found in [44]. A volume of $63 \mathrm{~cm}^{3}$ of oven-dried powder was charged in the drum, corresponding to a filling ratio of $40 \%$. All tests were performed at ambient humidity, between $46 \%$ and $55 \%$. A rotational speed of $0.0083 \mathrm{~s}^{-1}$ was selected because it (i) provided a sufficient number of events to allow the representation of data in the form of statistical distributions while (ii) allowing each event to be identified accurately while avoiding the overlap between particle tumbling and bulk rotation at the same rates (which typically occurs at high rotational speeds). This drum speed was, therefore, sufficiently slow to allow individual avalanches to occur independently.

When using rotating drum systems to characterize powder flow, a commonly used bulk motion indicator is the angle of the air/powder interface with the horizontal plane [14,45-47]. This indicator can successfully describe the motion of non-cohesive materials, as a smooth and linear surface generally develops at low rotational speeds. In contrast, due to the marked irregularity of the interface profile for cohesive powders, a 'centroid angle' $(\alpha)$ was used in this study. This angle is defined as the angle between the center of gravity of the powder and the center of the drum (Figure $2 \mathrm{~b}$ ). Using $\alpha$ as a motion indicator allows the accurate detection of avalanching movements, which are characterized by a rapid drop in the value of $\alpha$ [44]. From the temporal evolution of $\alpha$, several flow parameters can be estimated, using a peak identification algorithm, to identify the local maximum and minimum values of $\alpha$. 
The angle, $\alpha$, varies between the maximum and minimum values during an event. The maximum angle before an event is called the upper angle of stability $(U A S)$, and the value of $\alpha$ after the event corresponds to the lower angle of stability (LAS). UAS is an indicator of the inter-particle frictional forces that particles must overcome to slide across and over each other or to break away from the main body to create an avalanche. Angles of stability are homologous to angles-of-repose (AoRs) in static measurements; therefore, higher $U A S$ values and wider $U A S$ distributions generally correspond to decreased flowability.

The percentage of revolutions required to trigger events $(f)$ was also determined, as follows:

$$
f=\omega T 100 \%
$$

where $T$ is the time (s) required to trigger events and $\omega$ is the rotational speed $\left(\mathrm{s}^{-1}\right)$.

A larger $f$ value generally indicates increased powder cohesion because the events are less frequent. Powder with small $f$ distribution values should flow freely and require less energy to trigger flow. Powders that exhibit sharp and narrow $f$ distributions are generally easy-flowing and are preferable to work with than those displaying plateaus and broader distributions [18].

The duration of events $(\Delta t)$ was evaluated according to the elapsed time between $U A S$ and $L A S$ states. $\Delta t$ is a good indicator of the type of phenomena occurring during avalanches and was used by Li et al. [16] to study the granular avalanches of glass beads under slumping conditions $\left(0.00017 \mathrm{~s}^{-1}<\omega<0.0013 \mathrm{~s}^{-1}\right)$, in a quasi-2D packed drum.

The mere use of flow descriptors, such as $U A S$ or $f$, could result in similar conclusions, in terms of flow behavior, for samples with very different surface profiles. Consequently, to derive accurate conclusions regarding the ease of flow, visual inspections of the type of motion occurring in the powder bed are also important [48]. In this study, the coefficient of determination, $r^{2}$, of the linear regression for the powder profile was used as a criterion to quantify the irregularity of the interface. Powders that flow well generally pack well, forming a surface that is smoother, resulting in an $r^{2}$ value close to 1 . Cohesive powders will instead tend to form agglomerates when tumbling, so their surfaces are expected to be rougher and more irregular, leading to $r^{2}$ values lower than 1 . 


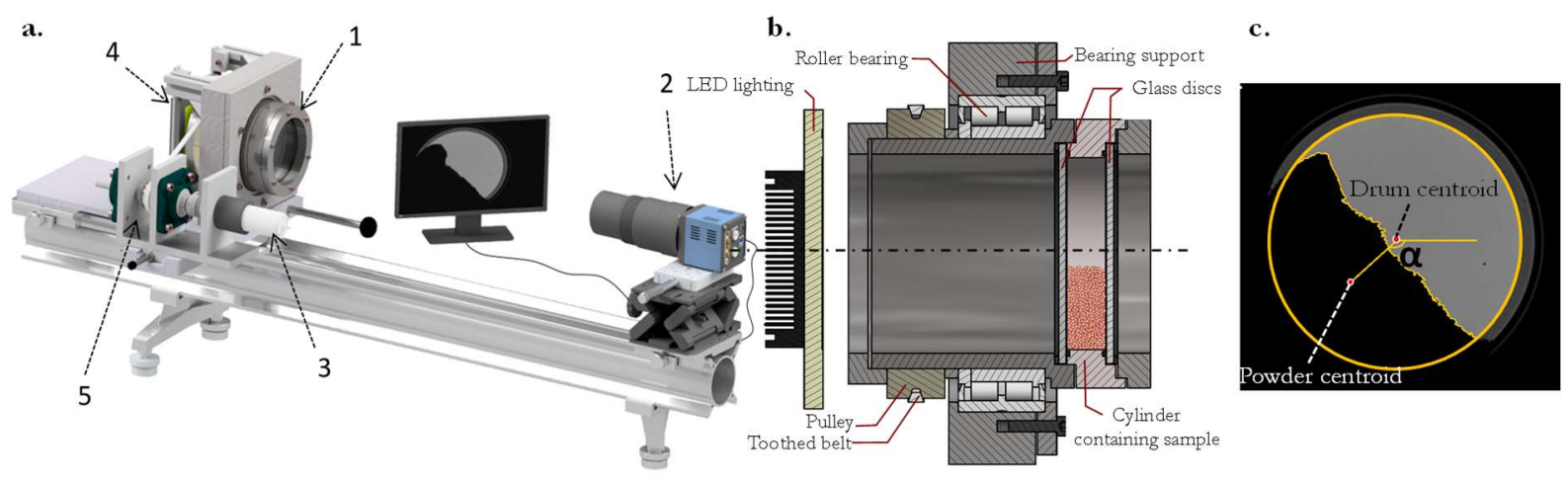

Figure 2. Rotating drum system. a. Experimental setup: 1: rotating cylinder, 2: high-speed camera, 3: motor, 4: lighting panel, 5. drive system, b. Detailed view of the cylinder c. Centroid angle $(\alpha)$ definition

\section{RESULTS AND DISCUSSION}

\subsection{Ring shear tests}

The yield loci obtained for all samples, at $\sigma_{p r e}=5 \mathrm{kPa}$, are shown in Figure $3 \mathrm{a}$ and $\mathrm{b}$, for coarse and fine sieving cuts, respectively. Overall, the yield loci of the fine samples were higher than those of the coarse powders, indicating that the stress required for failure is greater for fine samples. In addition, for both size populations, torrefaction intensity effects were also observed, with higher yield loci corresponding with the most intense thermal treatments.

By applying Mohr stress analysis to the yield locus plots, the values for the unconfined yield strength $\left(\sigma_{c}\right)$ and the major principal stress of consolidation $\left(\sigma_{1}\right)$ were obtained. From these values, the flow functions, presented in Figure $4 \mathrm{a}$ and b, were drawn. 
a.

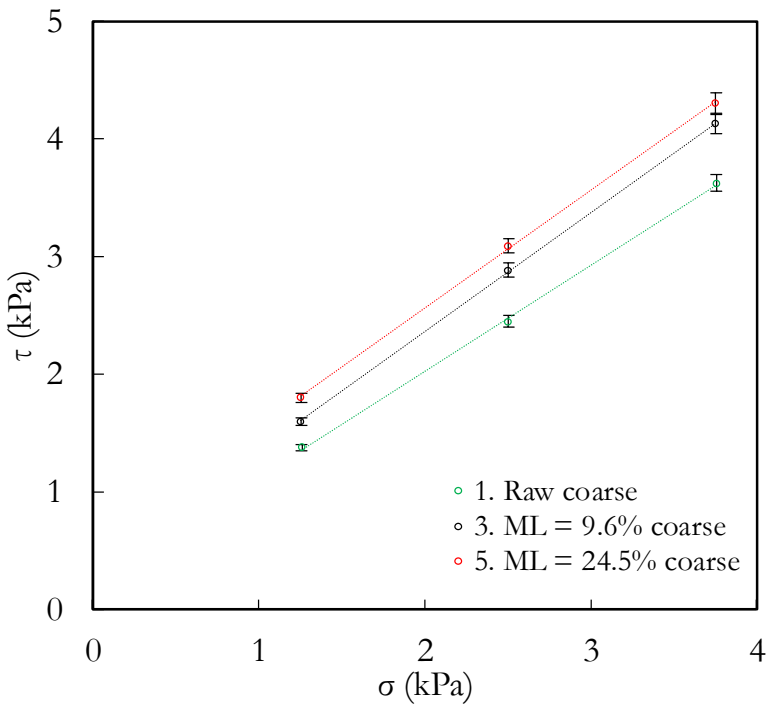

b.

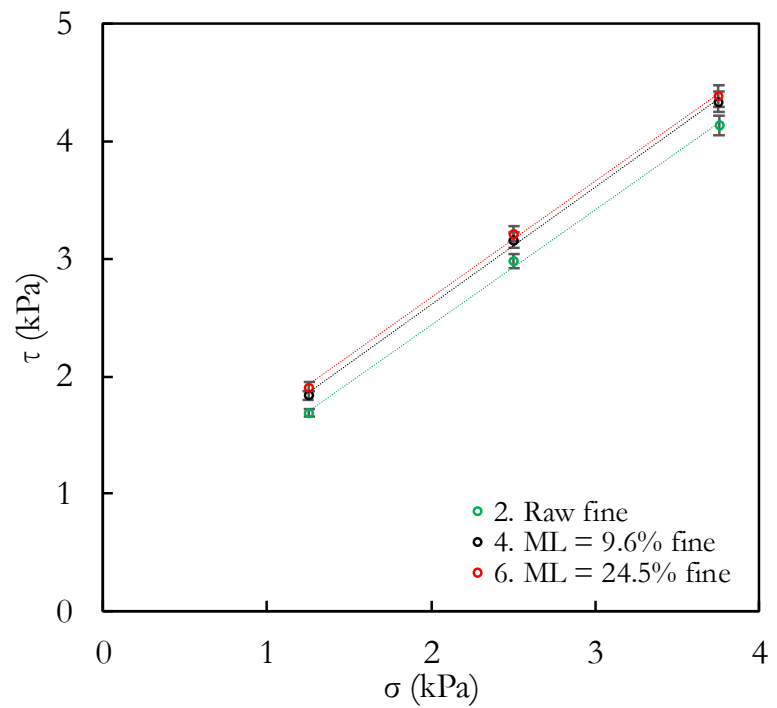

Figure 3. Yield loci at $\sigma_{p r e}=5 \mathrm{kPa}$. a. Coarse sieving cut. b. Fine sieving cut.

The flow function diagram represents the strength of the material at the free surface and reveals the tendency of a granular material to form a cohesive arch inside a hopper. Flow functions are not necessarily linear, so instead of drawing linear regressions, the 3 points corresponding to the 3 preshear stresses studied were connected with smoothed curves to ease the visualization in Figure 4a-b.
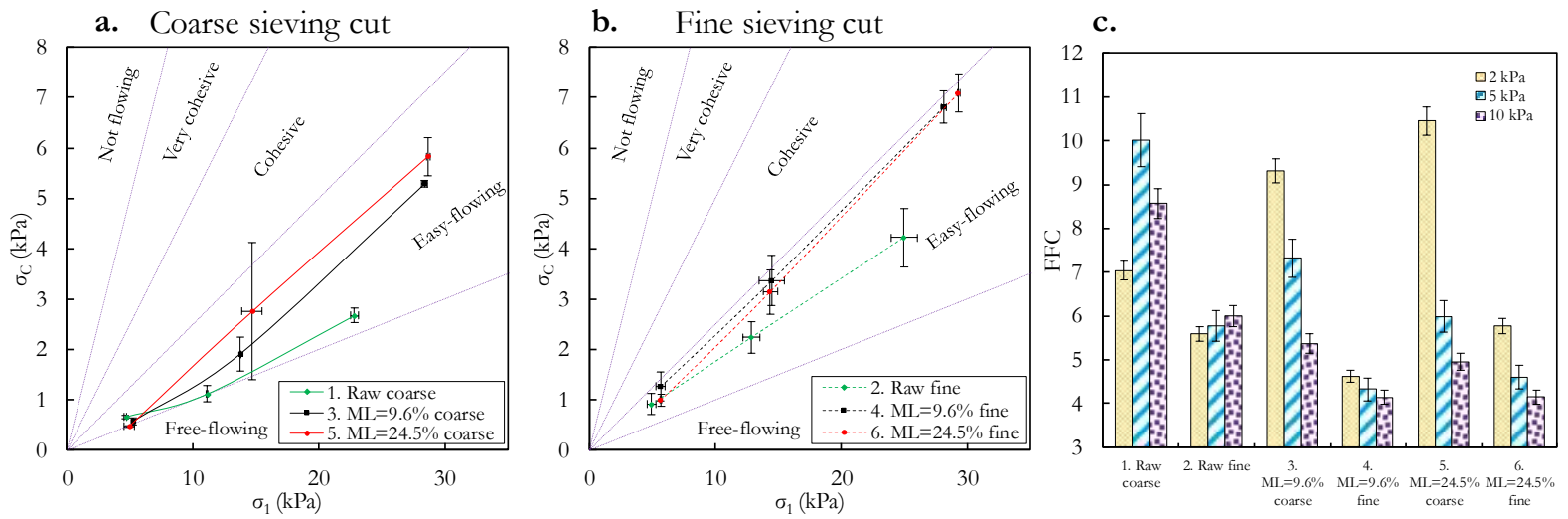

Figure 4. $a$ and b. Flow functions for coarse and fine sieving cuts, respectively. c. Flowability factor, FFC, for the biomass powders.

Although the flow functions were all located in the 'easy-flowing' region, according to the Jenike classification [49], the raw coarse powder was almost 'free-flowing', whereas the fine torrefied samples were nearly in the 'cohesive' region. Some trends could, therefore, be identified. First, for the same torrefaction intensity, the flow functions for finer materials were always higher than those for coarse materials, indicating that the particles in the fine sieving cuts had higher cohesive strengths. Second, the flow functions for the torrefied powders were located at higher values than 
those for raw samples. For torrefied samples, the error bars of the flow functions overlapped, preventing clear distinctions regarding the cohesiveness of these powders, based on these representations.

The curves in Figure 4a and $\mathrm{b}$ intersect and overlap within the range of stresses studied. In addition, because the drawn flow functions are based on a limited number of preshear stresses, general conclusions and flowability ranks should not be determined exclusively from these flow function diagrams. An analysis of the flowability factor, FFC (Figure 4c), may be more relevant.

The trends described above were found to be partially stress-dependent. For the same torrefaction intensity and preshear stress values, fine powders always demonstrated reduced flowability relative to coarse powders. For coarse samples, at an $\sigma_{\text {pre }}$ of $2 \mathrm{kPa}$, flowability increased with increasing torrefaction intensity. At $\sigma_{\text {pre }}$ values of 5 and $10 \mathrm{kPa}$, this trend reversed, with raw samples flowing better than torrefied samples, which suggests that for coarse samples, torrefaction improves flowability only under low-stress conditions. High-stress conditions should be avoided when storing or discharging torrefied materials. For the fine sieving cuts, the raw powder flowed better for all consolidation stresses compared with torrefied powders, and minimum flowability was observed for the mildly torrefied sample 4.

Interestingly, the FFC results revealed a decrease in flowability with an increase in consolidation for torrefied powders, regardless of the sieving cut, although this decrease was greater for coarse samples. For most common materials, flow functions always show a decreasing slope as the consolidation stress increases, resulting in increased flowability with increased consolidation (as is the case for sample 2) [50]. The particular behavior of torrefied biomass powders was observed by [51] for hemp hurds, primarily caused by the flexible nature of the plate-shaped particles. At high consolidation stresses, particles might change their orientations and adjust their shapes as they 'snuggle' together, which leads to plastic deformations of the total bulk solid and the more intensive overlapping of particles, increased transferable friction forces, and higher yield strengths. The rearrangement of particles to form a failure plan is facilitated by small particle dimensions, which may explain the smaller variations observed for FFC with increasing consolidation for the finer sieving cuts (samples 4 and 6).

Overall, the fine sieving cut of a mildly torrefied powder (sample 4) had the lowest flowability. This material will be more susceptible to problems, such as bridging, agglomeration, and blockages, in compacted feeding systems. These results may appear to contrast with previous findings [41,52], in which torrefied powders demonstrated improved flowability compared with raw powders. Because the samples used in this study have been sieved to obtain two populations of distinct sizes, the results of this study are not fully comparable to those of previous studies. Polydispersity, therefore, also appears to play a role in flow characteristics and should be considered to precisely 
determine the influences of powder properties on flow behaviors. Considerations of the effects of particle size, shape, and polydispersity are made in section 3.5 .

\subsection{Dynamic free-surface conditioning: Rotating drum tests}

\subsubsection{Categorization of events}

Figure 5 compares a typical centroid angle sequence for glass beads, which are a non-cohesive reference material (diameter $=1 \mathrm{~mm}$ ), and two examples of biomass powders (samples 1 and 5). Overall, very different flow dynamics were observed between cohesive and non-cohesive materials in a rotating drum. For the non-cohesive glass beads, at a speed of $0.0083 \mathrm{~s}^{-1}$, a continuous flow pattern was almost fully developed, suggesting that the particles rolled uniformly over a layer of particles on the surface and only very small variations in the angle occurred [44]. In contrast, for the cohesive biomass powders, a pattern developed between (i) 'large' quasi-periodic events, with angle differences of up to $20^{\circ}$, and (ii) random events with small variations in $\alpha$, reaching only a few degrees ('small' events). Small events were especially visible for the raw powder.

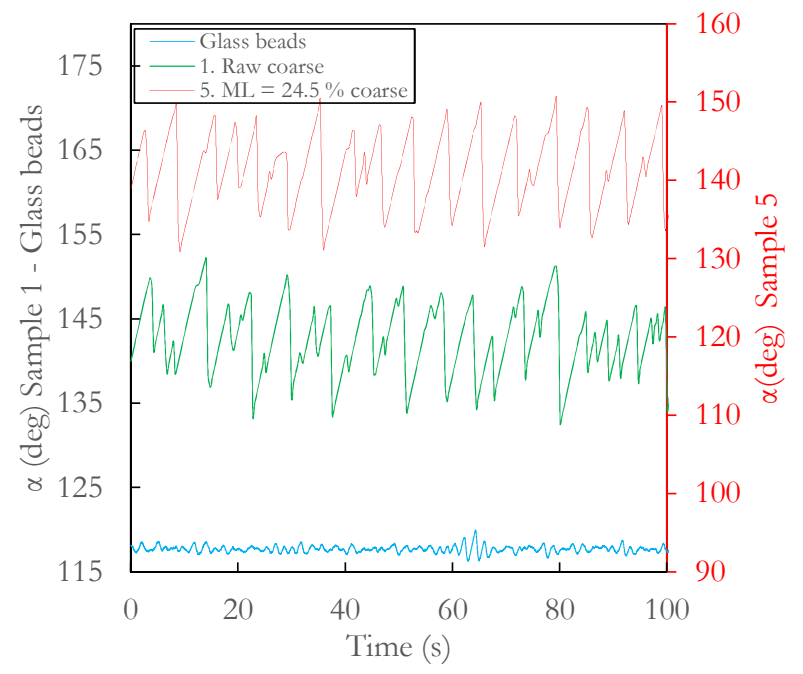

Figure 5. Typical evolution of the centroid angles for two examples of biomass powders and non-cobesive glass beads. Note that values for sample 5 are on the right $y$-axis.

An analysis of the event categories that occur during powder rotation is important for assessing flowability descriptors. Indeed, two distinct event categories were detected by the visual observation of avalanche activity during rotation. These events are illustrated by the image sequences for sample 1 (raw coarse) and sample $5(M L=24.5 \%$ coarse), shown in Figure 6. During large events, the particles in sample 1 formed relatively stable clumps that slumped and collapsed together over the powder surface, forming a very rough and irregular profile at the end of the event (Figure 6c). The curved irregularities over the surface then act as trigger points for the forthcoming collapses, which 
occur in local regions. These small events correspond more to material failure or breaks than to a uniform, shear sliding event, and are short in time, with small angle variations. In Figure 5, these events can be identified by a succession of small 'precursor' avalanches, which are separated by short time intervals before a large avalanche. These small precursors contribute to the gradual smoothing of the surface. For the smooth surfaces, most grains simultaneously meet the condition of critical equilibrium, resulting in a large avalanche.

Although slumping was also observed in sample 5, during small events, particles tended to uniformly slide over the entire length of the profile (Figure 6g), resulting in very smooth profiles after events (Figure 6h). During larger events, particles moved due to the shear failure within the sample, sliding over the entire profile. Large events were, thus, predominant, as can be observed in the plot for sample 5 in Figure 5.

The assessment of flowability descriptors should consider the categories of events described above. If the $U A S$ criterion is used, for example, the analysis should be based on the maximum angles of stability that trigger large events, as these correspond with the critical equilibrium state of the entire bulk material. In contrast, when using timebased indicators, such as the period between events, considering both precursors and large events could provide a better sense of the powder dynamics. Of course, both types of events may occur simultaneously during an avalanche, which can make their identification challenging.

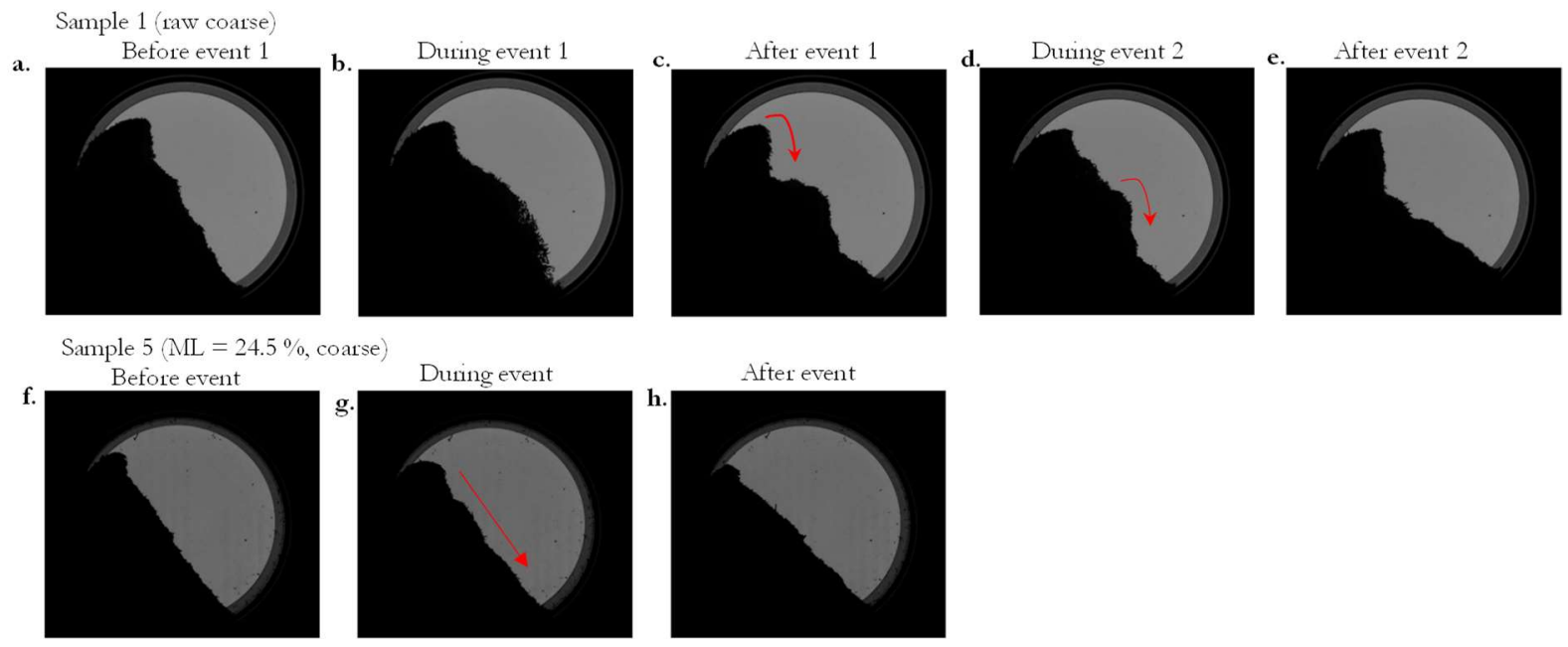

Figure 6. Flow inside the rotating drum for two biomass samples.

The durations of events were used in this study as indicators of their categories and are represented as frequency distributions in Figure 7. Fast events are likely to correspond to clumps breaking from irregular profiles, whereas large sliding events generally occur over longer periods of time. Two well-differentiated peaks show the occurrence of small and large events. The third peak, which is especially noticeable for sample 5 , at a duration of approximately $0.94 \mathrm{~s}$, corresponds with some exceptional sequence of large events. 
For the coarse samples, the slumping events, with durations of approximately $0.3 \mathrm{~s}$, are predominant for the raw and mildly treated samples (samples 1 and 3), whereas the shear sliding events, observed with durations of approximately $0.65 \mathrm{~s}$, prevail for the intensively torrefied powder (sample 5). These results corroborate the observations shown in Figure 5. Although small slumping events were dominant over large sliding events for all fine powder samples, the raw fine samples presented slumping events more frequently, followed by the mildly treated and intensively torrefied samples. Quantitatively, a flowability indicator, $\xi$, can be defined by the following equation:

$$
\xi=\frac{\text { Number of 'long' shear events }}{\text { Number of 'short' clumping events }}
$$

Lower values of $\xi$, indicate a tendency to form stable clumps of particles, which break on the free surface of the bulk material and result in irregular profiles, typical of cohesive powders. The $\xi$ values for the six biomass samples are listed in Table 2. Sample 5 stands out due to its high tendency for homogeneous sliding events, whereas sample 4 was the most likely to form cohesive clusters of particles.

Quantitatively, the average values flowability indicator distributions, as well as their widths (as measured by a span ratio), can be used as flowability indicators. Average values were obtained from the 50th percentile of the cumulative distributions and the span ratio, $S_{\varepsilon}$, for the descriptor $\varepsilon$ is given by the following equations

$$
S_{\varepsilon}=\frac{\varepsilon_{90}-\varepsilon_{10}}{\varepsilon_{90}+\varepsilon_{10}}
$$

where $\varepsilon_{90}$ and $\varepsilon_{10}$ are the 90 th and 10 th percentiles of the cumulative $\varepsilon$ distributions, respectively.

Table 2. Values of the flowability descriptors for biomass powders in a rotating drum setup. Span values are indicated in round brackets and flowability rankings are reported in square brackets.

\begin{tabular}{lcccc}
\hline \multicolumn{1}{c}{ Sample } & $\xi$ & $U A S_{50}\left(S_{U A S}\right)(\mathrm{deg})$ & $f_{50}\left(S_{f}\right)(\%)$ & $r_{50}^{2}\left(S_{r 2}\right)$ \\
\hline 1. Raw coarse & $1.012[\mathbf{I I}]$ & $146.3(2.8)[\mathbf{I I}]$ & $5.45(0.68)[\mathbf{I I}]$ & $0.966(0.030)[\mathbf{I I}]$ \\
2. Raw fine & $0.712[\mathbf{V}]$ & $149.1(2.8)[\mathbf{I V}]$ & $6.08(0.74)[\mathbf{V}]$ & $0.944(0.046)[\mathbf{V}]$ \\
3. $M L=9.6 \%$ coarse & $0.967[\mathbf{I V}]$ & $148.2(3.3)[\mathbf{I I I}]$ & $5.72(0.66)[\mathbf{I I I}]$ & $0.956(0.040)[\mathbf{I I I}]$ \\
4. $M L=9.6 \%$ fine & $0.571[\mathbf{V I}]$ & $153.3(3.0)[\mathrm{VI}]$ & $6.83(0.73)[\mathbf{V I}]$ & $0.929(0.051)[\mathrm{VI}]$ \\
5. $M L=24.5 \%$ coarse & $3.288[\mathbf{I}]$ & $146.2(3.2)[\mathbf{I}]$ & $5.79(0.77)[\mathbf{I V}]$ & $0.991(0.014)[\mathbf{I}]$ \\
6. $M L=24.5 \%$ fine & $0.994[\mathbf{I I I}]$ & $151.1(2.5)[\mathbf{V}]$ & $4.62(0.74)[\mathbf{I}]$ & $0.947(0.030)[\mathbf{I V}]$ \\
\hline
\end{tabular}


a.

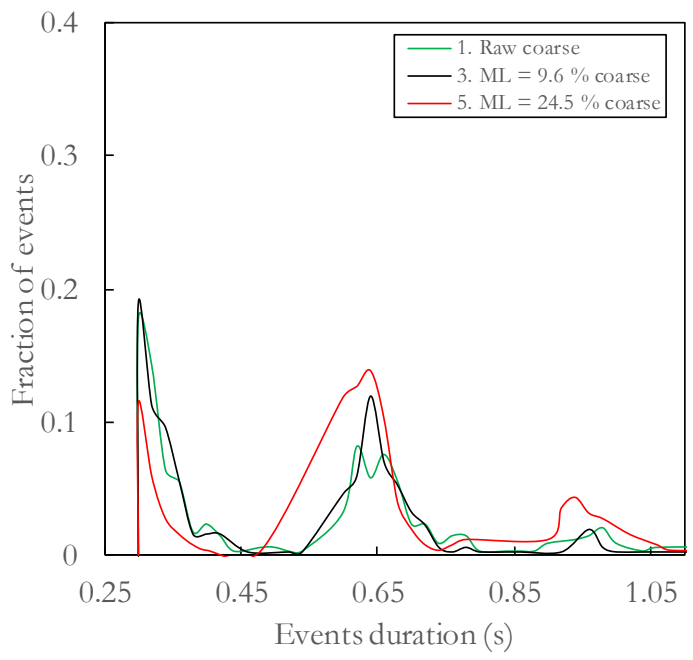

b.

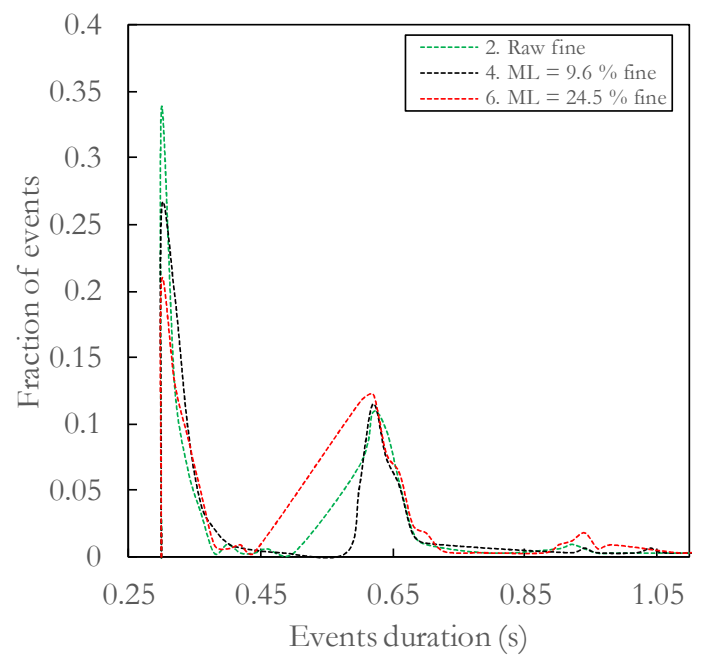

Figure 7. Events durations for coarse (a) and fine (b) biomass powders.

\subsubsection{UAS distributions}

The distributions shown in Figure 8 were calculated using the $U A S$ values corresponding to large events. Whereas non-cohesive materials exhibited unimodal and steep cumulative distributions, increased cohesiveness is usually accompanied by a rightward shift in the $U A S$ distribution. The $U A S$ distributions for the fine sieving cuts are systematically located at higher values than those for the coarse sieving cuts, indicating improved flowability for biomass powders made of coarse particles. Mildly torrefied samples have the most right-handed distributions, followed by the intensively torrefied powders, and the raw samples appeared to have the best flow behaviors, in terms of $U A S$. 


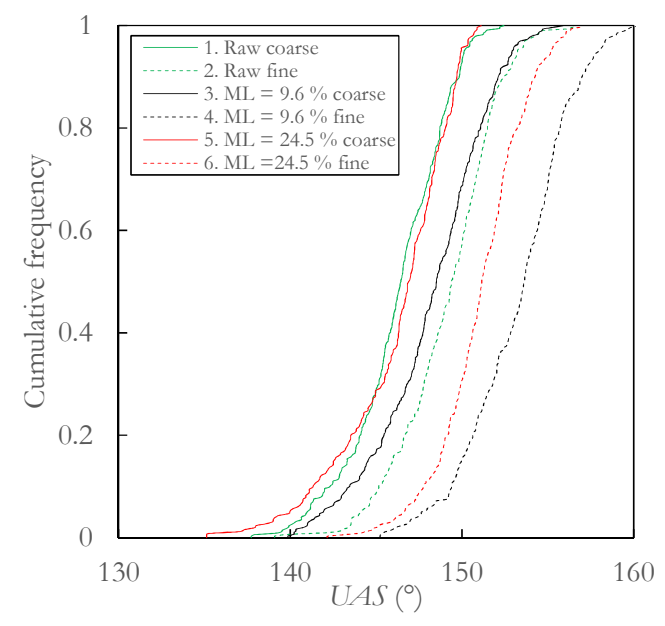

Figure 8. UAS distributions for both sieving fractions of raw, mildly, and intensively torrefied samples.

The avalanching behaviors of cohesive powders, particularly the $U A S$ values, are highly correlated with the uniformity of flow in screw feeders [25]. Materials must build up at the end of the screw until it collapses, so fine, mildly torrefied powders are likely to have highly variable flow rates, whereas the flow is likely to be more even for coarse materials. Values for the $50^{\text {th }}$ percentiles $\left(U A S_{50}\right)$ and spans $\left(S_{U A S}\right)$ of the $U A S$ distributions are reported in Table 2.

\subsection{3. f distributions}

The time between events (or period of avalanche) is generally used as a flowability criterion and is commonly reported without consideration for the types of events occurring inside the drum $[13,17,48,53-56]$. Similar to the period of avalanche, the fraction of revolutions required to trigger events $(f)$ is an indicator of particle flow dynamics and is likely to detect changes in flow conditions when the rotation speed changes. Periods of avalanche are, thus, normalized by considering the effects of the rotational speed (Eq. 4). Figure 9 compares the fraction of revolution values required to trigger events among the six samples, when all events are considered (Figure 9a) and when only the 'large' events are considered (Figure 9b). Overall, according to Figure 6a, sample 5 required a higher fraction of revolution value to trigger events, indicating that the events tended to occur less frequently than for the other powders studied, whereas the events for sample 1 were triggered more frequently. These results, considered alone, would lead to the conclusion that powder 5 has the lowest flowability. However, the categories of events must be considered, as described above. Although the frequency of events is lower for sample 5, the avalanches correspond with large sliding events, rather than with clump breakings, which is an indicator of better flow behavior. Therefore, although the frequency of events and the time elapsed between events are generally considered to be good indicators of flowability in rotating drums, the findings presented here highlight the importance of considering the visual observations of the types of motion, to derive accurate conclusions regarding the ease of flow. Similar conclusions were drawn by Lee et al. [48]. Figure 9b 
shows the fraction of revolution values necessary to trigger events when only large events are considered. The distributions are, thus, closer and may overlap and intersect in some regions, indicating that similar dynamics were obtained for different samples and making it more difficult to visually establish a ranking or flowability trend. The values of the $50^{\text {th }}$ percentile $\left(f_{50}\right)$ of the distributions presented in Figure $9 \mathrm{~b}$ are reported in Table 2 . The fine powders had larger $f_{50}$ values, on average, for raw and mildly torrefied samples, indicating more cohesive behaviors. The $f_{50}$ values for highly torrefied samples indicated that events were more frequently triggered for the fine sieve cut powders.

a.

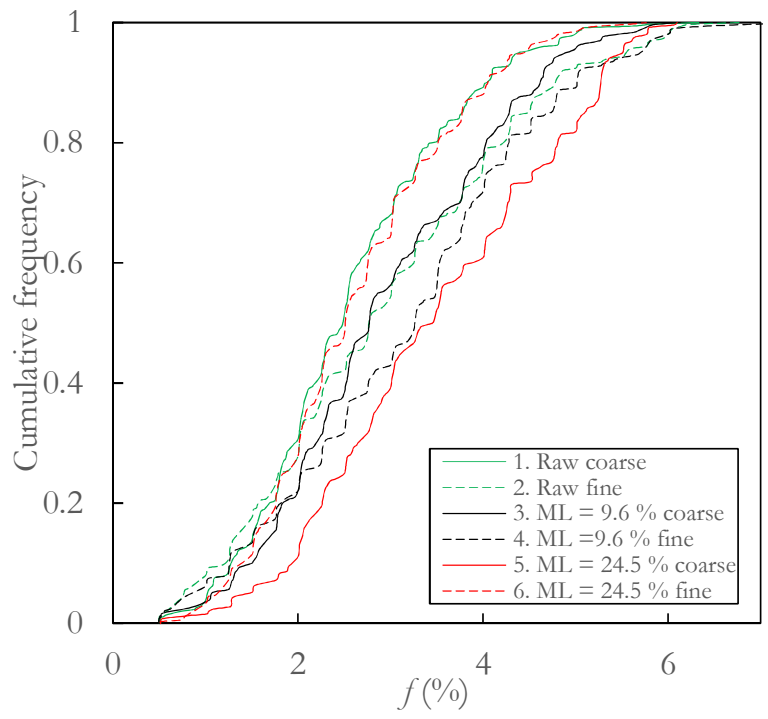

b.

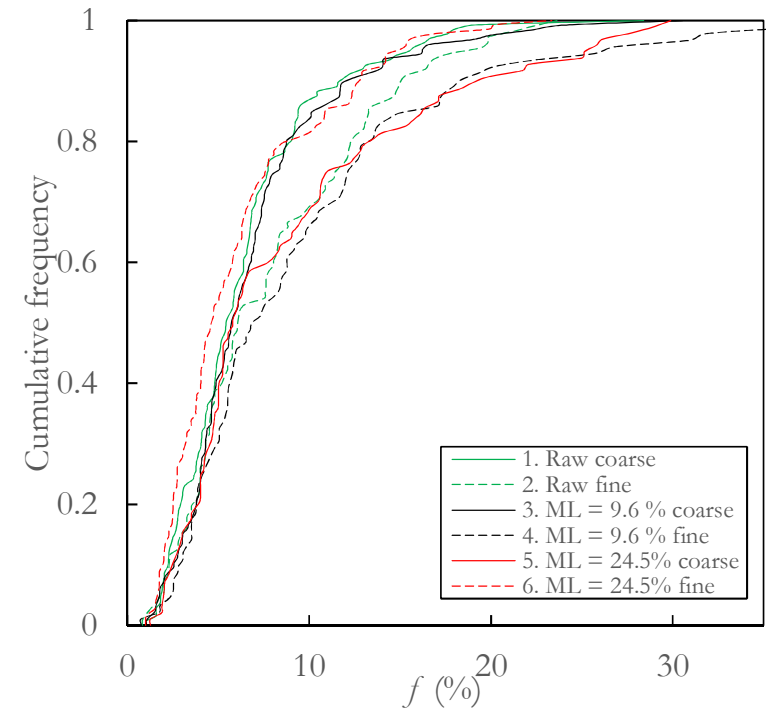

Figure 9. Distributions of the fraction of revolution values required to trigger events. a. All events. b. Only large events.

\subsubsection{Irregularity of powder bed profile, $r^{2}$}

Figure 10a shows an example of the temporal evolution of the coefficient of determination, $r^{2}$, for samples 4 and 5 , which exhibited radically different behaviors. Due to the predominant sliding events, the powder surface of sample 5 was always relatively smooth, resulting in $r^{2}$ values closer to 1 than for sample 4 . Figure $10 \mathrm{~b}$ compares the cumulative distributions of $r^{2}$ values for the six samples. Coarse samples presented more regular and smooth powder profiles, whereas fine powders had irregular and rough profiles, characteristic of cohesive behavior. According to the $r^{2}$ indicator, sample 5 displayed the least cohesive behavior and showed the lowest tendency to form clumps of particles, whereas sample 4 is likely to form clusters of particles that cause irregular flow. The average $r^{2}$ values and the span of distribution values are reported in Table 2 . 

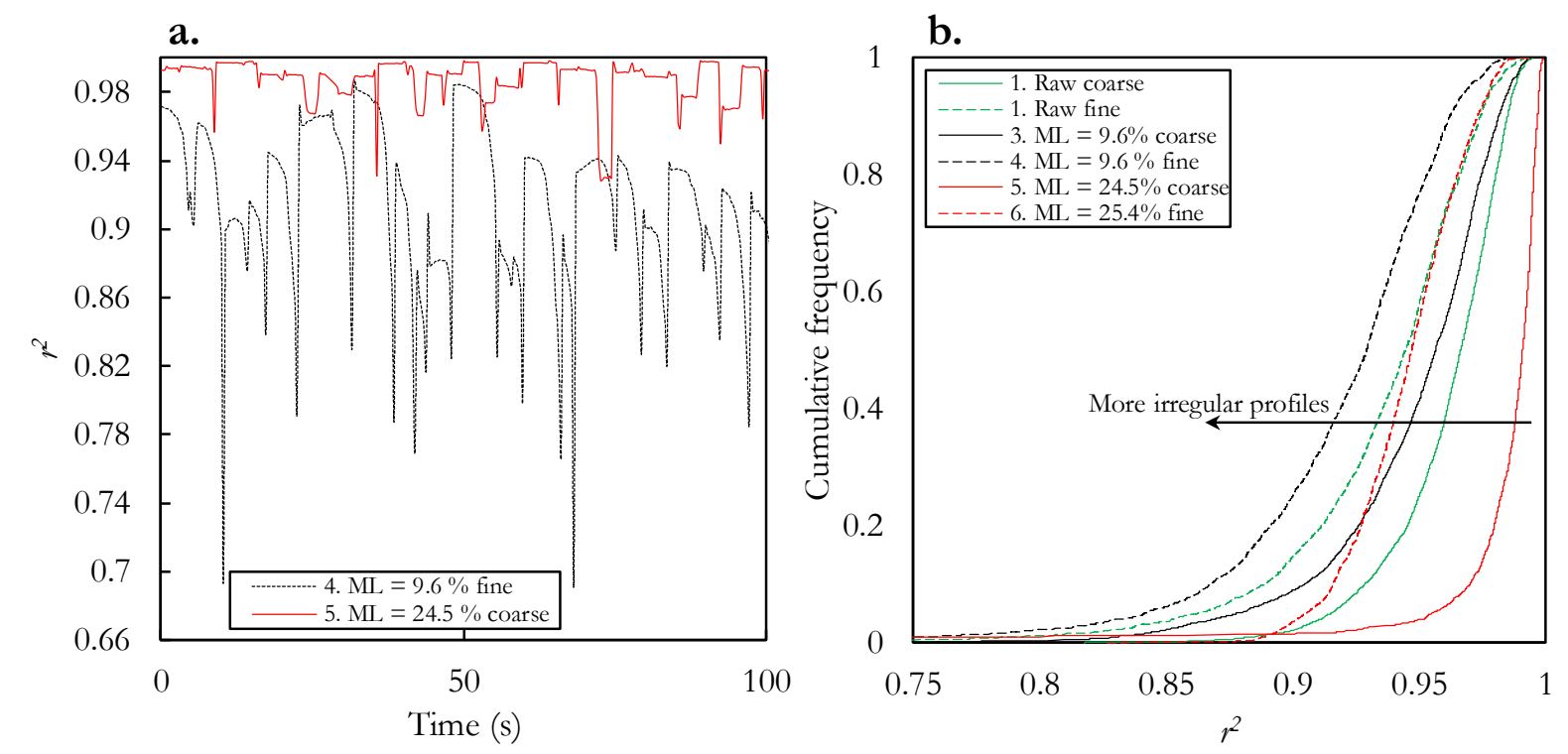

Figure 10. Coefficient of determination, $r^{2}$. a. Evolution, over time, of $r^{2}$ values for two powders. $b$. Cumulative distributions.

A flowability ranking for the six powders was established, according to the different criteria obtained from avalanching behavior analysis. This ranking is indicated in square brackets for each parameter in Table 2. Overall, the fine, mildly torrefied powder (sample 4) exhibited the worst flow behavior, with the greatest tendency to form clumps of particles, larger stability angles, greater $f$ values, and the most irregular powder profiles. In contrast, the intensively torrefied coarse sample (sample 5) had the best flowability, according to three of the four descriptors used.

Comparisons between the flowability ranking that can be established from the results at low consolidation stress $(2 \mathrm{kPa})$, from the shear test results, and the rankings obtained from avalanching behavior, using $r^{2}$ values as an indicator were performed. From the shear test results, samples were ranked, from best to worst flow behavior, as follows: 5, 3, 1, 6, 2, and 4. From rotating drum test results, the rankings were as follows: 5, 1, 3, 6, 2, 4. Low-stress and free-surface conditions led to similar flowability rankings. However, given the valuable insights regarding dynamic flow behaviors that avalanching tests provided, both static and dynamic characterization techniques should be employed to completely understand the flow properties of biomass powders and to predict their behaviors under different processing conditions [45]. 


\subsection{Discussion of the effects of particle characteristics}

The experimental results shown above revealed distinct flow behaviors among samples. These differences are likely the result of combined effects between particle properties and the consolidation state during flow. Particle properties are determined by the intensity of the torrefaction treatment and by the sieving stage. Mean particle size and shape, as well as the PSD span, are considered to be the primary particle characteristics that affect flow properties. Several observations can be made, based on the results presented above.

- Fine materials were always found to have a greater cohesiveness, under both consolidated and loose packing conditions. Therefore, flowability appears to be inversely correlated with particle size. Fine particles have larger specific surface areas, allowing van der Waals forces of attraction to become dominant, which decreases the flowability of the powder samples [57].

- Mildly torrefied samples (numbers 3 and 4 ) had especially low flowability. These samples were also among the samples with the lowest circularity and aspect ratio values (Table 1). As indicated in a previous study [41], particle shape is likely to significantly affect the flow properties of raw and torrefied biomass powders. Samples with irregular shapes are, thus, expected to have greater cohesiveness, resulting in lower flowability factors, higher angles of stability, and more irregular powder profiles after avalanches. Elongated and less rounded particle shapes are, therefore, likely to partially explain the poor flow behaviors of the mildly torrefied samples.

- The span of the PSD may have important effects on powder behaviors. An attempt was made to limit its effects in this study, by performing the sieving step; however, the intensively torrefied samples still presented relatively broad PSDs.

Based on these observations, the power laws of Eqs. 7 to 9 were developed, to correlate particle characteristics (mean particle size, the span of the size distribution, and mean aspect ratio) with the average values of three flowability criteria: FFC, $U A S_{50}$, and $r_{50}^{2}$. Using Microsoft Excel's Solver functionality, the four parameters of each flowability descriptor, $i\left(m_{i}, a_{i}, b_{i}\right.$, and $\left.c_{i}\right)$ were fitted using the experimental data. These values are listed in Table 3.

$$
F F C_{10 k P a}=m_{F F C} x_{50}^{a_{F F C}}\left(S_{x}^{b_{F F C}}\right)^{-1} a_{50}^{c_{F F C}}
$$




$$
U A S_{50}=m_{U A S}\left(x_{50}^{a_{U A S}} S_{x}^{b_{U A S}} a_{50}^{c_{U A S}}\right)^{-1}
$$

$$
r_{50}^{2}=m_{r^{2}} x_{50}^{a^{2}} S_{x}^{b^{2}} a_{50}^{c^{2}}
$$

Figure 11 shows that Eqs. 7 to 9 correctly described the relationships between powder characteristics and the flowability descriptors.

In Eq. 7, the values of FFC at $\sigma_{\text {pre }}=10 \mathrm{kPa}$ were chosen as representative of a highly consolidated state. Eq. 7 indicates that the flowability, as measured by the ring shear tester, is directly related to the mean particle size and aspect ratio and inversely related to the PSD span, which is in agreement with the physical observations described above. Zulfiqar et al. [58], in their study on the flow properties of biomass and coal blends, established that the flow of a polydispersed bulk solid primarily depends on the strength of the fine particle fraction. Therefore, among powder samples with similar mean sizes, those with larger PSD ranges are likely to have stronger particle to particle cohesion and lower FFC values [51], which could explain the relatively low FFC values obtained for samples 5 and 6 under high consolidation conditions, despite their rounder and less elongated shapes. This result is in good agreement with earlier findings reported for other powdered materials [59,60].
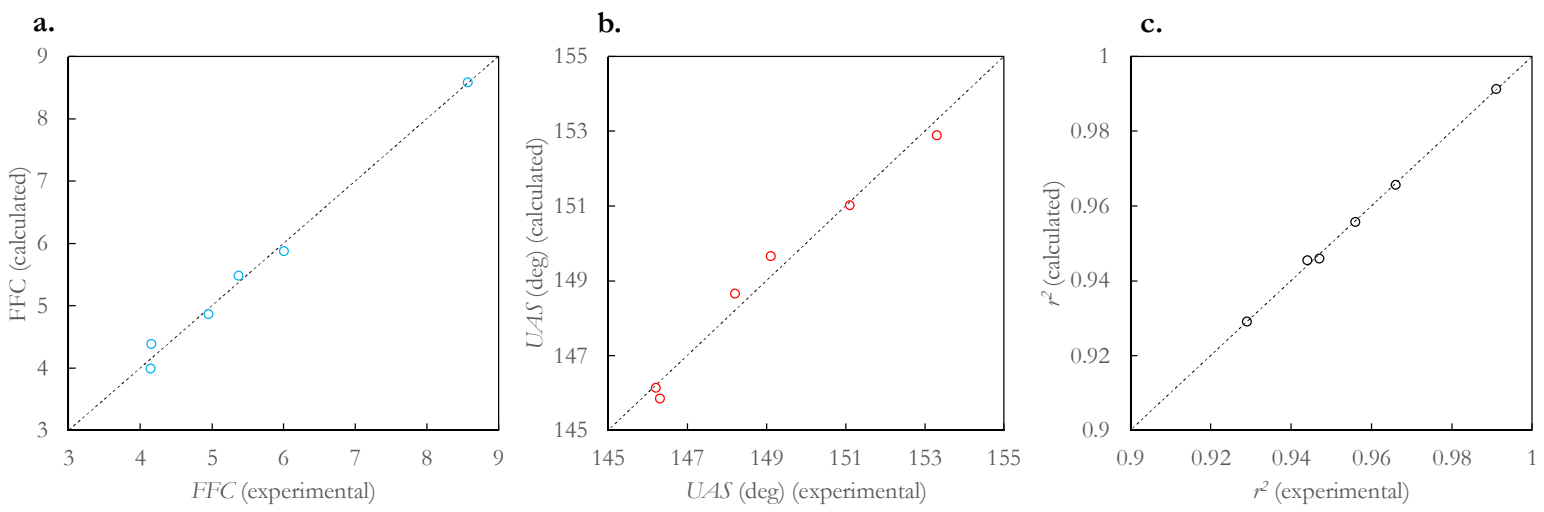

Figure 11. Experimental and calculated values of three flowability descriptors. The dotted line corresponds to the diagonal $x=y$. 
Table 3. Parameters of the power-law relationships (Eqs. 2 to 4) for three flowability descriptors.

\begin{tabular}{lllll}
\hline$i$ & $m_{i}$ & $a_{i}$ & $b_{i}$ & $c_{i}$ \\
\hline FFC & 0.10 & 0.72 & 1.55 & 1.99 \\
$U A S_{50}$ & 174.96 & 0.04 & 0.03 & 0.07 \\
$r_{50}^{2}$ & 0.91 & 0.03 & 0.12 & 0.02 \\
\hline
\end{tabular}

Eqs. 8 and 9 indicate that fine, rough, and needle-shaped particles, as well as powders with narrow PSD ranges, result in more cohesive behaviors. Interestingly, increasing the powder polydispersity appears to improve flow properties under non-consolidated, free-surface conditions. The relatively good flow behaviors observed for the intensively torrefied samples (samples 5 and 6) could, therefore, be the combined result of the more rounded particle shapes and the higher PSD span. In a free-surface, dynamic flow, fine particles within a polydispersed population may act, to some extent, as flow agents that reduce the tendency of large particles to entangle and interlock.

Although the relationships described by Eqs. 7 to 9 are consistent with the experimental data, caution should be exercised with respect to the potential influences of other particle properties or process conditions that were not assessed in this study. In addition to size and shape modifications, torrefaction is likely to alter the surface properties of biomass powders. The hydrophobic nature of torrefied samples could affect the flow properties, by altering electrostatic forces. First, because the presence of bound water lowers the electrical resistivity, raw samples (which tend to capture moisture more easily) will tend to drain electrostatic charges better than processed samples. Secondly, as indicated in previous research [61], the electrostatic properties of the particles are directly related to the surface functional group chemistry, with hydrophobic groups accumulating greater quantities of charge than hydrophilic groups. Therefore, when all other parameters are the same, torrefied samples are more likely to present flow problems, due to charge build-up. Flow problems induced by the accumulation of electrostatic charges are primarily expected during free-surface flows or when the powder contacts non-conductive surfaces. Although particular care was taken during the design of the rotating drum to limit the effects of electrostatic charges, reduced electrical drainage among torrefied powders may also explain the reduced flowability of samples 3 and 4 (in addition to their more elongated and rough shapes). Among highly torrefied samples, the positive effects on the flowability of both a large PSD span and a more rounded shape might overcome the negative effects of the charge build-up. 


\section{CONCLUSION}

This study investigated the flow behaviors of raw and torrefied biomass powders, using a ring shear tester and a rotating drum setup. Fine materials always demonstrated increased cohesiveness. If the material is to be handled or stored under high consolidation stress conditions, the results from the shear tests suggested that raw, coarse powders are less likely to present flow problems. However, the FFC results were found to be stress-dependent, and at low stresses, intensively torrefied coarse powders flowed better.

This study demonstrated relationships between several flowability indicators and particle characteristics, such as particle shape, mean size, and the PSD span for raw and torrefied biomass powders, under two different flow conditions. Four flowability criteria were determined $\left(\xi, U A S, f\right.$, and $\left.r^{2}\right)$ allowing the six samples to be ranked for flow characteristics. The derived power laws fitted the experimental data well and corresponded with the expected physical behaviors and observations from previous research. These results highlighted the multivariate and highly interdependent effects that should be considered when assessing the flowability of biomass materials.

The most cohesive powders had a greater tendency to form clumps of particles that flowed badly, whereas shear sliding events were characteristic of good flow behavior. Overall, intense torrefaction appears to improve the flow behaviors of powders, both under free-surface and consolidated conditions. Fine, mildly torrefied powders exhibited the worst flow behavior, whereas the intensively torrefied coarse sample had the best flowability. These behaviors could be explained through the analysis of particle characteristics and their effects on flow.

\section{Appendix A. Flow property measurements, using shear testers}

The theory underlying the use of shear testing to evaluate the flow properties of powdered materials has been described, in detail, in [51]; however, a brief summarization is included, here, for a better understanding of the subject.

According to the standard procedure, once the shear cell containing the powder sample has been prepared, the maximum normal preshear stress, $\sigma_{\text {pre }}$, is applied to the cell lid. The pre-shearing step is performed until a steady-state value of shear stress is attained, at which point the frictional forces between particles are maximal, with respect to the applied normal load. At this point, the powder attains a well-defined and reproducible state of consolidation, 
corresponding to the top point in Figure 12. This steady-state often occurs when the sample volume and its bulk density, $\rho_{b}$, reach steady-state values, at the end of compaction [51]. After the preshearing step, the direction of shear is reversed, and the shear stress is reduced to zero. Then, the normal stress is reduced to a value $\sigma_{s b, 1}<\sigma_{p r e}$, and the specimen is sheared until a peak value of shear stress, $\tau_{s b}$, is reached (incipient flow or failure) [10]. This two-step is then repeated, with the same $\sigma_{p r e}$ and increasing $\sigma_{s h .}$. Finally, a verification point, at $\sigma_{s h, 1}$, is determined. The $(\sigma, \tau)$ couples obtained at failure are drawn to represent the yield locus, corresponding to the applied consolidation.

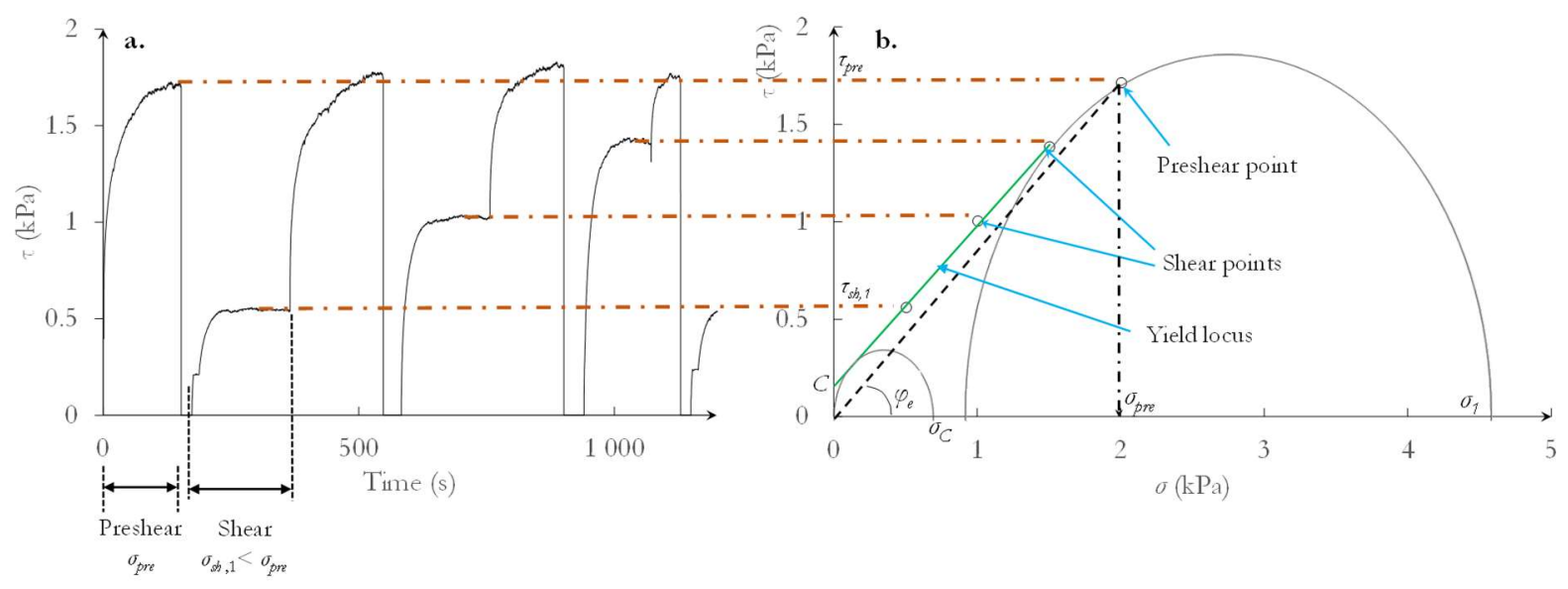

Figure 12. Shear stress testing for sample 1, at $\sigma_{p r e}=2 \mathrm{kPa}$. a. Evolution of the shear stress over time. $b$. Yield locus construction and Mohr circles, defining unconfined yield strength $\left(\sigma_{c}\right)$ and consolidation stress $\left(\sigma_{1}\right)$.

As represented in Figure 12, the Mohr circle, drawn through the steady-state point and tangential to the yield locus, locates the major principal stress, $\sigma_{1}$, corresponding to the applied consolidation. The unconfined yield strength $\left(\sigma_{c}\right)$ is given by the major principal stress, passing through the origin and tangential to the yield locus. In Figure 12, the dashed line passing the origin and tangential to the larger Mohr circle represents the effective yield locus. Its angle of inclination with respect to the $\sigma$-axis is the effective angle of internal friction $\varphi_{e}$. The yield locus for a non-cohesive granular material passes through the origin; therefore, cohesion, $C$, corresponds to the value of the shear stress where the yield locus intersects with the $\tau$ axis (when the normal stress $\sigma=0$ ). For a full investigation of the flow properties of bulk solids, plots similar to the one displayed in Figure 12 should be prepared for a range of initial consolidation loads, resulting in a series of yield loci [62]. Flow functions ( $\sigma_{c}$ vs. $\left.\sigma_{1}\right)$ can then be drawn.

Appendix B. Considerations for the shear testing of biomass powders 
To produce accurate and reproducible yield loci using an annular shear tester, the material should reach a steady-state flow, defined as the plastic deformation of the bulk solid at constant shear stress and bulk density. Fibrous, flaky materials, such as biomass powders, may not achieve a steady-state flow during preshear stages. The material may also relax when the stress is relieved, before the shear stage, as can be observed in Figure 13a, presenting an increase in the lid displacement (equivalent to a decrease in the bed height and an increase in the bulk density), as the shear stress is removed between the pre-shear and the shear stages. As a result, the material is not over-consolidated when it is sheared to failure, resulting in a lower yield locus and the underestimation of the unconfined yield strength. Instead of a sharp maximum $\tau$ when shearing, the curve reaches a plateau and resembles another pre-shear stage, at lower consolidation stress. Miccio et al. [7] stated that the absence of peak values during the shear stress stage may also be due to the slight expansion of the biomass sample at the end of the pre-shear stage (a slight decrease in lid displacement). However, in this study, this expansion was also present for samples that exhibited $\tau$ peaks at shear (Figure 13b). These observations are in agreement with previous research by $[7,25,63]$, who highlighted the particular behaviors of biomass powders during shear tests, compared with those of conventional elastoplastic solids.

This behavior was especially apparent for tests at low $\sigma_{\text {pre }}(2 \mathrm{kPa})$ for coarse sieving cuts, such as sample 1 , shown in Figure 13a. The yield loci were, therefore, calculated by using steady-state values for shear stress when peak values were not detected during the shear stages. Despite the above-mentioned peculiarities, $(\sigma, \tau)$ points showed good repeatability, and the corresponding yield loci could be linearized. Fine samples showed shear stress curves similar to those of common granular materials. An example is shown in Figure 13b (sample 6), where $\tau$ peak values during the shear stage can be observed.

a.

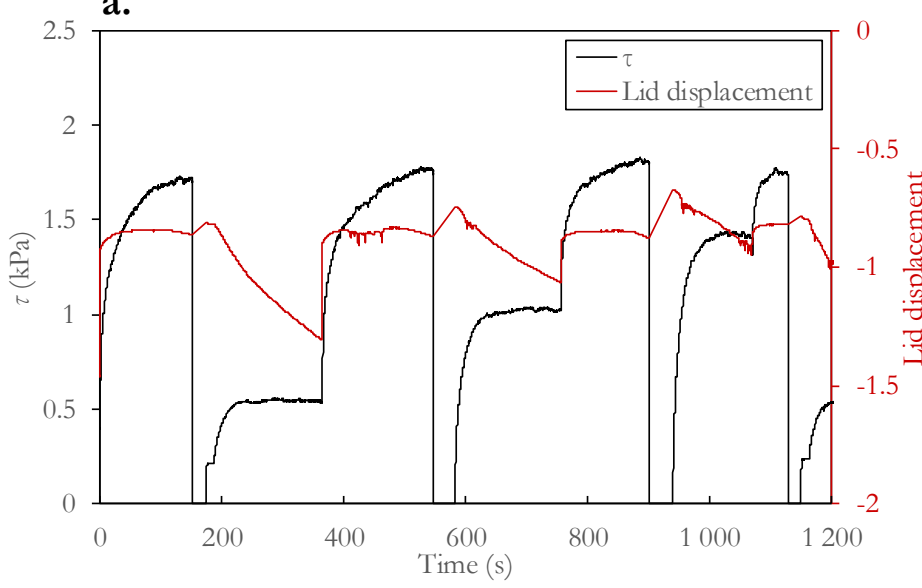

b.

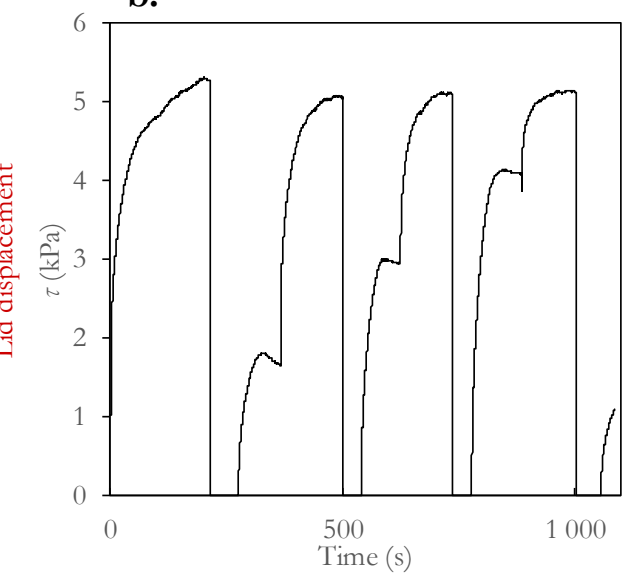

Figure 13. a. Shear stress and lid displacement during the shear test for Sample 1, at $\sigma_{\text {pre }}=2 \mathrm{kPa} . \mathrm{b}$. Shear stress evolution of Sample 6, at $\sigma_{\text {pre }}=$ 
Appendix C. List of symbols and acronyms

$a$ : aspect ratio

AoR: Angle of repose

$d_{p}$ : particle diameter, $\mu \mathrm{m}$

$d_{p 10}: 10^{\text {th }}$ centile of cumulative particle size distribution, $\mu \mathrm{m}$

$d_{p 50}: 50^{\text {th }}$ centile of cumulative particle size distribution, $\mu \mathrm{m}$

$d_{p 90}: 90^{\text {th }}$ centile of cumulative particle size distribution, $\mu \mathrm{m}$

$f$ fraction of revolution required to trigger events

FFC: Flow function coefficient

fps: frames per second

DEM: Discrete Element Method

$L A S$ : Lower angle of stability

ML: Mass loss, $\%$

PSD: Particle size distribution

$U A S$ : Upper angle of stability

$r^{2}$ : coefficient of determination of linear regression

$S_{x}$ : particle size distribution span

$S_{a}$ : aspect ratio distribution span

$S_{\Phi: ~}$ Circularity span

SRF: Short Rotation Forestry

\section{Greek letters}

$\alpha$ : centroid angle

$\zeta$ : ratio of small events/large events 
$\theta$ : angle of the slope for powder-free surface, from linear regression

६: flowability descriptor

$\sigma$. consolidation stress, normal stress, $\mathrm{kPa}$

$\sigma_{s s}:$ Shear (normal) stress, $\mathrm{kPa}$

$\tau$ : shear stress, tangential stress, $\mathrm{kPa}$

$\Phi:$ circularity

$\omega$ : angular velocity, rotational speed

\section{References}

[1] P. Bergman, A. Boersma, J. Kiel, M.J. Prins, K. Ptasinski, F.J. Janssen, Torrefaction for entrained-flow gasification of biomass, 2nd World Conf. Technol. Exhib. Biomass Energy, Ind. Clim. Prot. a (2005) 78-82. http:/ /www.ecn.nl/publications/PdfFetch.aspx?nr=ECN-RX--04-029\#page=78.

[2] J. Dai, H. Cui, J.R. Grace, Biomass feeding for thermochemical reactors, Prog. Energy Combust. Sci. 38 (2012) 716-736. doi:10.1016/j.pecs.2012.04.002.

[3] M. Asadullah, Barriers of commercial power generation using biomass gasification gas: A review, Renew. Sustain. Energy Rev. 29 (2014) 201-215. doi:10.1016/j.rser.2013.08.074.

[4] A.W. Jenike, Gravity flow of bulk solids, (1961). https://collections.lib.utah.edu/details?id=709033 (accessed January 2, 2019).

[5] J. Schwedes, Review on testers for measuring flow properties of bulk solids, Granul. Matter. 5 (2003) 1-43. doi:10.1007/s10035-002-0124-4.

[6] ASTM International, D6773-02: Standard Test Method for Bulk Solids Using Schulze Ring Shear Tester 1, Annu. B. ASTM Stand. (2002) 1-26. doi:10.1520/D6682-08.

[7] F. Miccio, D. Barletta, M. Poletto, Flow properties and arching behavior of biomass particulate solids, Powder Technol. 235 (2013) 312-321. doi:10.1016/j.powtec.2012.10.047. 

stover, Fuel Process. Technol. 112 (2013) 76-85. doi:10.1016/j.fuproc.2013.02.024.

[9] Z. Guo, X. Chen, Y. Xu, H. Liu, Study of flow characteristics of biomass and biomass-coal blends, Fuel. 141 (2015) 207-213. doi:10.1016/j.fuel.2014.10.062.

[10] B. Littlefield, O.O. Fasina, J. Shaw, S. Adhikari, B. Via, Physical and flow properties of pecan shells-Particle size and moisture effects, Powder Technol. 212 (2011) 173-180. doi:10.1016/j.powtec.2011.05.011.

[11] N. Chevanan, A.R. Womac, V.S.P. Bitra, C. Igathinathane, Y.T. Yang, P.I. Miu, S. Sokhansanj, Bulk density and compaction behavior of knife mill chopped switchgrass, wheat straw, and corn stover, Bioresour. Technol. 101 (2010) 207-214. doi:10.1016/j.biortech.2009.07.083.

[12] N.C. Crawford, N. Nagle, D.A. Sievers, J.J. Stickel, The effects of physical and chemical preprocessing on the flowability of corn stover, Biomass and Bioenergy. 85 (2016) 126-134. doi:10.1016/j.biombioe.2015.12.015.

[13] R.G. Iacocca, R.M. German, The experimental evaluation of die compaction lubricants using deterministic chaos theory, Powder Technol. 102 (1999) 253-265. doi:10.1016/S0032-5910(98)00217-4.

[14] Y.L. Xiao, E. Specht, J. Mellmann, Experimental study of the lower and upper angles of repose of granular materials in rotating drums, Powder Technol. 154 (2005) 125-131. doi:10.1016/j.powtec.2005.04.040.

[15] J. Mellmann, The transverse motion of solids in rotating cylinders-forms of motion and transition behavior, Powder Technol. 118 (2001) 251-270. doi:10.1016/S0032-5910(00)00402-2.

[16] R. Li, H. Yang, G. Zheng, Q.C. Sun, Granular avalanches in slumping regime in a 2D rotating drum, Powder Technol. 326 (2018) 322-326. doi:10.1016/j.powtec.2017.12.032.

[17] H. Yang, G.L. Jiang, H.Y. Saw, C. Davies, M.J. Biggs, V. Zivkovic, Granular dynamics of cohesive powders in a rotating drum as revealed by speckle visibility spectroscopy and synchronous measurement of forces due to avalanching, Chem. Eng. Sci. 146 (2016) 1-9. doi:10.1016/j.ces.2016.02.023.

[18] V.R. Nalluri, M. Kuentz, Flowability characterisation of drug-excipient blends using a novel powder avalanching method, Eur. J. Pharm. Biopharm. 74 (2010) 388-396. doi:10.1016/j.ejpb.2009.09.010.

[19] A.W. Alexander, B. Chaudhuri, A. Faqih, F.J. Muzzio, C. Davies, M.S. Tomassone, Avalanching flow of cohesive powders, Powder Technol. 164 (2006) 13-21. doi:10.1016/j.powtec.2006.01.017. 
[20] M.A.S. Quintanilla, J.M. Valverde, A. Castellanos, The transitional behaviour of avalanches in cohesive granular materials, J. Stat. Mech. Theory Exp. (2006). doi:10.1088/1742-5468/2006/07/P07015.

[21] S.C. Thakur, J.Y. Ooi, M.B. Wojtkowski, O.I. Imole, V. Magnanimo, H. Ahmadian, E.C. Montes, M. Ramaioli, Characterisation of cohesive powders for bulk handling and dem modelling, 3rd Int. Conf. Part. Methods Fundam. Appl. Part. 2013. (2013) 310-321. doi:10.1063/1.4812098.

[22] V. Jaggi, M.C. Leaper, A. Ingham, Measuring the flow properties of small powder samples using an avalanche tester, Dry. Technol. 34 (2016) 723-728. doi:10.1080/07373937.2015.1072093.

[23] E. Emery, J. Oliver, T. Pugsley, J. Sharma, J. Zhou, Flowability of moist pharmaceutical powders, Powder Technol. 189 (2009) 409-415. doi:10.1016/j.powtec.2008.06.017.

[24] M. Wojtkowski, O.I. Imole, M. Ramaioli, E. Chaóvez Montes, S. Luding, Behavior of cohesive powder in rotating drums, AIP Conf. Proc. 1542 (2013) 983-986. doi:10.1063/1.4812098.

[25] J. Falk, R.J. Berry, M. Broström, S.H. Larsson, Mass fl ow and variability in screw feeding of biomass powders — Relations to particle and bulk properties, Powder Technol. 276 (2015) 80-88. doi:10.1016/j.powtec.2015.02.023.

[26] K. Svoboda, M. Pohořelý, M. Hartman, J. Martinec, Pretreatment and feeding of biomass for pressurized entrained flow gasification, Fuel Process. Technol. 90 (2009) 629-635. doi:10.1016/j.fuproc.2008.12.005.

[27] M. Phanphanich, S. Mani, Impact of torrefaction on the grindability and fuel characteristics of forest biomass, Bioresour. Technol. 102 (2011) 1246-1253. doi:10.1016/j.biortech.2010.08.028.

[28] T.G. Bridgeman, J.M. Jones, A. Williams, D.J. Waldron, An investigation of the grindability of two torrefied energy crops, Fuel. 89 (2010) 3911-3918. doi:10.1016/j.fuel.2010.06.043.

[29] B. Arias, C. Pevida, J. Fermoso, M.G. Plaza, F. Rubiera, J.J. Pis, Influence of torrefaction on the grindability and reactivity of woody biomass, Fuel Process. Technol. 89 (2008) 169-175. doi:10.1016/j.fuproc.2007.09.002.

[30] J. Pachón-Morales, J. Colin, F. Pierre, T. Champavert, F. Puel, P. Perré, Flowability of lignocellusic biomass powders: Influence of torrefaction intensity, EPJ Web Conf. 140 (2017). doi:10.1051/epjconf/201714013017.

[31] J.E. Mattsson, P.D. Kofman, Method and apparatus for measuring the tendency of solid biofuels to bridge 
over openings, Biomass and Bioenergy. 22 (2002) 179-185. doi:10.1016/S0961-9534(01)00067-8.

[32] S. Paulrud, J.E. Mattsson, C. Nilsson, Particle and handling characteristics of wood fuel powder: Effects of different mills, Fuel Process. Technol. 76 (2002) 23-39. doi:10.1016/S0378-3820(02)00008-5.

[33] J. Pachón-Morales, P. Perré, J. Casalinho, H. Do, D. Schott, F. Puel, J. Colin, Potential of DEM for investigation of non-consolidated flow of cohesive and elongated biomass particles, Adv. Powder Technol. (2020). doi:10.1016/j.apt.2020.01.023.

[34] Y.H. Jung, H.J. Cho, J.S. Lee, E.W. Noh, O.K. Park, K.H. Kim, Evaluation of a transgenic poplar as a potential biomass crop for biofuel production, Bioresour. Technol. 129 (2013) 639-641. doi:10.1016/j.biortech.2012.12.074.

[35] D. Dickmann, Poplar culture in North America, NRC Research Press, 2001.

[36] J. Colin, Séchage en continu du bois énergie comme moyen de conditionnement en vue de sa conservation thermochimique : approches expérimentale et numérique, AgroParisTech, 2011. https://pastel.archivesouvertes.fr/pastel-00861231.

[37] J. Pachón-Morales, J. Colin, F. Pierre, F. Puel, P. Perré, Influence de l'épaisseur de particule sur l’homogénéité de traitement thermique d’un bois de peuplier, Récents Progrès En Génie Des Procédés SFGP. 110 (2017) 1-7.

[38] P. Perré, R. Rémond, I. Turner, A comprehensive dual-scale wood torrefaction model: Application to the analysis of thermal run-away in industrial heat treatment processes, Int. J. Heat Mass Transf. 64 (2013) 838849. doi:10.1016/j.ijheatmasstransfer.2013.03.066.

[39] F. Pierre, G. Almeida, F. Huber, P. Jacquin, P. Perré, An original impact device for biomass characterisation: Results obtained for spruce and poplar at different moisture contents, Wood Sci. Technol. 47 (2013) 537555. doi:10.1007/s00226-012-0512-9.

[40] G. Almeida, D.V.B. Santos, P. Perré, Mild pyrolysis of fast-growing wood species (Caribbean pine and Rose gum): Dimensional changes predicted by the global mass loss, Biomass and Bioenergy. 70 (2014) 407-415. doi:10.1016/j.biombioe.2014.07.028.

[41] J. Pachón-Morales, J. Colin, F. Pierre, F. Puel, P. Perré, Effect of torrefaction intensity on the flow properties of lignocellulosic biomass powders, Biomass and Bioenergy. 120 (2019) 301-312. doi:10.1016/j.biombioe.2018.11.017. 
[42] Sympatec, QICPIC GmbH, (2018). https://www.sympatec.com/en/particlemeasurement/sensors/dynamic-image-analysis/qicpic/ (accessed July 11, 2018).

[43] D. Schulze, Ring Shear Tester RST-XS - Operating instructions, 2012.

[44] J. Pachón-Morales, J. Colin, J. Casalinho, F. Puel, P. Perré, Investigation on criteria for assessment of flowability of cohesive and non-cohesive powders using a rotating drum, Submitt. to Chem. Eng. J. (2019) 1-32.

[45] M. Krantz, H. Zhang, J. Zhu, Characterization of powder flow: Static and dynamic testing, Powder Technol. 194 (2009) 239-245. doi:10.1016/j.powtec.2009.05.001.

[46] R. Fischer, P. Gondret, M. Rabaud, Transition by intermittency in granular matter: From discontinuous avalanches to continuous flow, Phys. Rev. Lett. 103 (2009) 2-5. doi:10.1103/PhysRevLett.103.128002.

[47] G. Lumay, F. Boschini, K. Traina, S. Bontempi, J.C. Remy, R. Cloots, N. Vandewalle, Measuring the flowing properties of powders and grains, Powder Technol. 224 (2012) 19-27. doi:10.1016/j.powtec.2012.02.015.

[48] Y.S. Lee, R. Poynter, F. Podczeck, J.M. Newton, Development of a dual approach to assess powder flow from avalanching behavior., AAPS PharmSciTech. 1 (2000) E21. doi:10.1208/pt010321.

[49] A.W. Jenike, Gravity flow of bulk solids, (1961). https://collections.lib.utah.edu/details?id=709033 (accessed July 11, 2018).

[50] D. Schulze, Flow properties of powders and bulk solids (fundamentals), Powder Technol. 65 (2010) 321333.

[51] D. Schulze, Powders and Bulk Solids, Springer Berlin Heidelberg, Berlin, Heidelberg, 2007. doi:10.1007/978-3-540-73768-1.

[52] J. Pachón-Morales, J. Colin, F. Pierre, T. Champavert, F. Puel, P. Perré, Flowability of lignocellusic biomass powders: Influence of torrefaction intensity, EPJ Web Conf. 140 (2017) 0-3. doi:10.1051/epjconf/201714013017.

[53] J.Y.S. Tay, C.V. Liew, P.W.S. Heng, Powder Flow Testing: Judicious Choice of Test Methods, AAPS PharmSciTech. 18 (2017) 1843-1854. doi:10.1208/s12249-016-0655-3.

[54] A. Crouter, L. Briens, The Effect of Moisture on the Flowability of Pharmaceutical Excipients, AAPS PharmSciTech. 15 (2014) 65-74. doi:10.1208/s12249-013-0036-0. 
[55] J.L.P. Soh, C. V. Liew, P.W.S. Heng, New indices to characterize powder flow based on their avalanching behavior, Pharm. Dev. Technol. 11 (2006) 93-102. doi:10.1080/10837450500464123.

[56] F. Lavoie, L. Cartilier, R. Thibert, New methods characterizing avalanche behavior to determine powder flow, Pharm. Res. 19 (2002) 887-893. doi:10.1023/A:1016125420577.

[57] E. Abdullah, D. Geldart, The use of bulk density measurments as a flowability, Powder Technol. 102 (1999) 151-165. doi:10.1017/CBO9781107415324.004.

[58] M. Zulfiqar, B. Moghtaderi, T.F. Wall, Flow properties of biomass and coal blends, Fuel Process. Technol. 87 (2006) 281-288. doi:10.1016/j.fuproc.2004.10.007.

[59] S.S. Mallick, L. Rohilla, V. Garg, G. Setia, Modeling flow properties of fine dry powders using particle morphological properties and its effects on geometry of fly ash evacuation hoppers, Part. Sci. Technol. 36 (2018) 464-472. doi:10.1080/02726351.2017.1367746.

[60] H. Lu, X. Guo, Y. Liu, X. Gong, Effect of particle size on flow mode and flow characteristics of pulverized coal, KONA Powder Part. J. (2015). doi:10.14356/kona.2015002.

[61] H. Yang, B.F. Zhang, R. Li, G. Zheng, V. Zivkovic, Particle dynamics in avalanche flow of irregular sand particles in the slumping regime of a rotating drum, Powder Technol. 311 (2017) 439-448. doi:10.1016/j.powtec.2017.01.064.

[62] C.R. Woodcock, J.S. Mason, Bulk Solids Handling : an Introduction to the Practice and Technology, Springer Netherlands, 1988.

[63] D. Barletta, R.J. Berry, S.H. Larsson, T.A. Lestander, M. Poletto, Á. Ramírez-Gómez, Assessment on bulk solids best practice techniques for flow characterization and storage/handling equipment design for biomass materials of different classes, Fuel Process. Technol. 138 (2015) 540-554. doi:10.1016/j.fuproc.2015.06.034. 